\title{
A Novel Receptor-type Protein Tyrosine Phosphatase Is Expressed during Neurogenesis in the Olfactory Neuroepithelium
}

\author{
Kevin M. Walton, * Karen J. Martell,* Seung P. Kwak,* \\ Jack E. Dixon, ${ }^{*+}$ and Brian L. Largent ${ }^{\dagger \neq}$ \\ * Department of Biological Chemistry \\ +Neuroscience Program \\ ₹Department of Anatomy and Cell Biology \\ The University of Michigan \\ Ann Arbor, Michigan 48109-0606
}

\section{Summary}

Tyrosine phosphorylation plays a central role in the control of neuronal cell development and function. Yet, few neuronal protein tyrosine phosphatases (PTPs) have been identified. We examined rat olfactory neuroepithelium for expression of novel PTPs potentially important in neuronal development and regeneration. Using the polymerase chain reaction with degenerate DNA oligomers directed to the conserved tyrosine phosphatase domain, we identified 6 novel tyrosine phosphatases. One of these, PTP NE-3, is a receptor-type PTP expressed selectively in both rat brain and olfactory neuroepithelium. In the olfactory neuroepithelium, PTP NE-3 expression is restricted to neurons and describes a novel pattern of expression with a high level in the immature neurons and a lower level in mature olfactory sensory neurons.

\section{Introduction}

The mammalian olfactory system is an exceptional model for the study of neurogenesis, plasticity and regeneration. While most neurons in adult mammals are terminally differentiated, olfactory sensory neurons have a limited life and are constantly regenerated from a stem cell population. The sensory neurons are maintained in a structurally simple pseudostratified columnar epithelium along with supporting sustentacular (glial-like) cells and basal cells (Graziadei and Monti-Graziadei, 1978; Morrison and Costanzo, 1990). The basal cells represent the stem cell population from which neural progenitor cells arise (Graziadei and Monti-Graziadei, 1978; Camera and Harding, 1984; Samanen and Forbes, 1984). As the progenitors differentiate into mature neurons, they migrate apically through the epithelium. A dendrite extends to the surface of the epithelium while an axon grows out of the base of the epithelium, fasciculates along the olfactory nerve, and forms a synapse in the olfactory bulb in the CNS.

Odorant information in the olfactory system is processed at several levels (Reed, 1992; Anholt, 1993). First, individual olfactory neurons respond to a limited number of odorants, since each sensory cell expresses only a very small subset of the available odorant receptors (Nef et al., 1992; Ngai et al., 1993; Ressler et al., 1993). Second, each olfactory sensory neuron must establish precise synaptic contact with a distinct subset of olfactory bulb neurons in the CNS to transmit sensory information properly (Oakley and Riddle, 1992). Consequently, an extremely high degree of fidelity is required in the continually renewed connections between olfactory neurons and the central nervous system. The molecular processes controlling olfactory neural regeneration remain largely unknown.

Over the past decade, it has become evident that tyrosine phosphorylation plays an important role in cellular signal transduction pathways. Many aspects of neuronal cell function are clearly regulated via tyrosylphosphorylation. For example, the receptors for nerve growth factor and its related family of neurotrophins (brain-derived nerve growth factor and neurotrophins-3, -4 , and -5 [NT-3, NT-4, and NT-5]) are all transmembrane receptor-linked tyrosine kinases (Barbacid et al., 1991; Kaplan et al., 1991; Klein et al., 1991; Rodriguez-Tebar et al., 1991; Chao, 1992; Ibáñez et al., 1992). These receptors are expressed almost exclusively in neurons in a developmentally regulated pattern, suggesting a role in neuronal development (Klein et al., 1989, 1990; Martin-Zanca et al., 1990). There is a neuron-specific form of the cytoplasmic tyrosine kinase, c-Src, and it is preferentially distributed in the growth cones and proximal axon shafts in neonate rat brain (Maness et al., 1988). Because tyrosylphosphorylation of tubulin by c-Src inhibits tubulin's ability to polymerize into microtubules, c-Src may regulate growth cone elongation (Maness and Matten, 1990; Matten et al., 1990).

Protein tyrosine phosphatases (PTPs), as the enzymatic counterpoint to tyrosine kinases, serve an important role in regulating tyrosylphosphorylation and, consequently, neuronal development and function. Analogous to the family of tyrosine kinases, there are both receptor-type and intracellular forms of PTPs. Genetic analyses have shown that PTPs can have important roles in development. The gene for the Drosophila PTP, corkscrew, is in the class of terminal genes required for the formation of the head and tail of the embryo (St. Johnston and Nüsslein-Volhard, 1992). Similarly, overexpression of the Dictyostelium phosphatase PTP1 results in severe morphological defects during development in the slime mold (Howard et al., 1992). Disruption of the gene for PTP1 induces an accelerated developmental time course.

Some PTPs have been localized to neurons. An intracellular PTP, STEP, is neural specific and highly enriched in the striatum of the brain (Lombroso et al., 1991). In Drosophila, three receptor-type PTPs are expressed in the developing embryonic nervous system (Streuli et al., 1989; Hariharan et al., 1991; Tian et al., 1991; Yang et al., 1991). Early in development, DPTP99A is expressed in several neurons that pioneer the intersegmental nerve (Yang et al., 1991). Later, both DPTP99A and DLAR can be identified in most axons, 
whereas DPTP10D is preferentially expressed in the anterior commissure and at its junctions with the longitudinal tracts (Tian et al., 1991). This pattern of expression strongly suggests a role for PTPS in axon pathfinding and stabilization.

Our goal in this study was to identify novel PTPS potentially involved in olfactory neuronal development and function. Such PTPs may be expressed exclusively in the olfactory neuroepithelium to serve the unique regenerative properties of the olfactory system. Alternatively, PTPs that serve generally in neural development may be found. These PTPS would have a continued expression in the adult olfactory system to subserve the continual neuronal turnover. Using the polymerase chain reaction (PCR) with degenerate DNA oligomer primers to highly conserved sequences within the phosphatase enzymatic domain, we have identified 6 novel PTPs expressed in olfactory tissue as well as 9 PTPs that have been cloned previously from other tissue sources. In this paper, we describe the full-length cDNA sequence, deduced primary amino acid structure, expression, and enzymatic activity of one of these clones, PTP NE-3, a receptor-type phosphatase. Two mRNA sizes were identified by Northern analysis, with the smaller message detected only in brain and olfactory neuroepithelium. The extracellular domain of PTP NE-3 has both immunoglobulin-like domains and fibronectin type III (FNIII) repeats, common to some receptor-type PTPS and to many cell adhesion molecules. In adult rat brain, PTP NE-3 is expressed at high levels in the pyramidal cells of the hippocampus and at lower levels in the thalamus, cerebral cortex, and cerebellum. In the olfactory neuroepithelium, it is expressed only in the olfactory neuronal lineage. PTP NE-3 expression describes a novel pattern of localization in these cells. In situ hybridization histochemistry reveals that PTP NE-3 is expressed at high levels in the immature neurons. It is also expressed in the mature sensory neurons but at a lower level. We propose that PTP NE-3 may have a role in creating the neuronal architecture of the mammalian olfactory system.

\section{Results}

\section{Molecular Cloning and Sequence Analysis of PTP NE-3, a Novel Receptor-type PTP}

First strand CDNA from rat olfactory neuroepithelium served as a template for PCR amplification with degenerate DNA oligomer primers directed at the phosphatase domain of PTPS. The PCR products contained a major band of approximately $\mathbf{2 8 0} \mathrm{bp}$ that was cloned into the pBluescript II vector (Stratagene). The nucleotide and predicted amino acid sequences of the cloned inserts were compared with those of previously cloned PTPs. From the 80 clones sequenced, 15 different phosphatases were identified (Table 1). Of the 9 PTPs that had been previously reported, 3 of these were receptor-type PTPS (PTPE, PTPy, and PTPס) (Krueger et al., 1990). Among the other 6 intracellular
Table 1. Fourteen Protein Tyrosine Phosphatases Identified by PCR from Olfactory Neuroepithelium

\begin{tabular}{lc}
\hline Phosphatase & Number of Isolates \\
\hline MLRP & 7 \\
PTPS & 6 \\
PTP MEG-01 & 1 \\
PTPH1 & 6 \\
PTP 1C & 15 \\
RPTP1 & 1 \\
PTP $\gamma$ & 3 \\
PTP & 12 \\
PTPE & 1 \\
Novel PTPs & \\
NE-1 & 1 \\
NE-2 & 3 \\
NE-3 & 3 \\
NE-4 & 4 \\
NE-5 & 1 \\
NE-6 & 2 \\
\hline
\end{tabular}

MLRP (Matthews et al, 1990), PTPS (Swarup ef al., 1991), PTP MEG-01 (Gu ef al., 1991). PTPH1 (Yang and Tonks, 1991), PTP 1C (Shen et al., 1991), RPTP1 (Guan et al., 1990), PTPy, PTPS, PTPE (Krueger ei al., 1990).

PTPs, 1 is an SH2-containing phosphatase (PTP 1C) (Shen et al., 1991), and 2 others, PTPH1 (Yang and Tonks, 1991) and PTP MEG-01 (Gu et al., 1991), have domains displaying homology with cytoskeletal proteins. Six of the 15 PTP clones were novel. Because of the small number of different cell types present in olfactory neuroepithelium, it is likely that each of the cell types expresses multiple phosphatases.

The tissue distribution of the novel PTPs was determined by RNAase protection assays (data not shown). Further characterization of PTP NE-3 was pursued since it was expressed at high levels solely in olfactory neuroepithelium and brain. A rat brain cerebral cortex, oligo(dT)-primed CDNA library was screened with a radiolabeled probe from the $280 \mathrm{bp}$ clone of PTP NE-3 obtained by PCR. A 4630 bp fragment of PTP NE-3 was isolated that included two PTP domains, a motif common in receptor-type PTPs. Since this clone was not full length, the library was rescreened using the $5^{\prime}$ end of this clone to identify a longer CDNA. This newly identified clone included all of the sequence of the first isolate along with an additional $660 \mathrm{bp}$ at the $5^{\prime}$ end of the clone. However, this second isolate also did not represent the full-length CDNA. The remaining coding sequence was obtained by the $5^{\prime}$ RACE PCR technique (Figure 1) (Frohman, 1990). DNA oligomers, designed to the $5^{\prime}$ end of the second isolate, were used in this reaction and resulted in the isolation of a $220 \mathrm{bp}$ clone. This clone included $96 \mathrm{bp}$ of new coding sequence including the initiating ATG codon, and 99 bp of 5 untranslated sequence. in addition, the clone obtained from the $5^{\prime}$ RACE technique had 25 bp of sequence overlapping with the second isolate, confirming its identity as additional PTP NE-3 sequence. A composite of the three isolates resulted in a sequence with a single open reading frame, giving a translated product of 1501 amino acid residues, a 
predicted mature protein of 1477 amino acid residues, and a calculated molecular mass of $168 \mathrm{kd}$. This composite clone had extensive sequence similarity with several receptor-type PTPs.

The putative initiating methionine of PTP NE-3 was determined by comparison of the nucleotide sequence with the Kozak consensus sequence (Kozak, 1991) and by comparison of the amino acid sequence following the putative initiating methionine with that described for signal peptides (Gierasch, 1989; von Heijne, 1990). The most invariant aspects of the Kozak sequence, an adenine or guanine at position -3 and a guanine at position +4 , can be identified adjacent to the putative initiating methionine codon of PTP NE-3 (Figure 1). The general structure of a signal peptide identifies a positively charged amino acid(s) within 10 residues after the methionine, followed by a hydrophobic stretch. Cleavage generally occurs at an alanine residue $20-25$ amino acids after the methionine. Each of these characteristics is evident in the putative signal peptide of PTP NE-3 (Figure 1). In addition, there is an in-frame stop codon upstream of the indicated initiating methionine. PTP NE-3 has two potential $\mathrm{N}$-linked glycosylation sites, at residues 250 and 295. A hydrophobic stretch of amino acids occurs at positions $851-875$ and is likely to be a transmembrane domain. There are two regions in the putative cytoplasmic portion of PTP NE-3 that reveal extensive sequence identity with the phosphatase domains of previously cloned PTPs.

Sequence similarity searches of the GenBank and EMBL data bases with the predicted amino acid sequence of PTP NE-3 identified human leukocyte antigen-related tyrosine phosphatase (PTP LAR) as having the greatest sequence identity with PTP NE-3 (Figure 2) (Streuli et al., 1988). The sequences of both PTP LAR and PTP NE-3 have three immunoglobulin-like domains at the amino-terminal end of their putative extracellular region. A hallmark of immunoglobulinlike domains is the 2 conserved cysteine residues per domain (Williams and Barclay, 1988). As indicated in Figure $2 \mathrm{~B}$, the positioning of these residues is conserved between PTP NE-3 and LAR. Carboxy-terminal to the immunoglobulin-like domains, LAR has eight FN-III domains. However, PTP NE-3 contains only four FN-III domains. A gap in the sequence alignment between PTP NE-3 and LAR indicates that, although PTP NE-3 has FN-III domains that align with domains I, II, III, and VIII of LAR, domains IV, V, VI, and VII are not present in PTP NE-3. Interestingly, these four missing FN-III domains are perfectly excised from the PTP NE-3 sequence, as the end of domain III is directly adjacent to the start of domain VIII. A comparison of the potential N-glycosylation sites between LAR and PTP NE-3 reveals that in the portion of the LAR sequence that aligns with PTP NE-3, LAR has three potential N-glycosylation sites. Two of these align with potential $\mathrm{N}$-glycosylation sites at amino acids 250 and 295 of PTP NE-3. The other potential N-glycosylation site in LAR aligns with a threonine (amino acid 117) in PTP
NE-3. The indicated initiating methionine of LAR is not the same as the one that has been previously identified (Streuli et al., 1988), which is at position 11 of the LAR sequence presented in Figure 2. This is suggested both by the sequence similarity of LAR and PTP NE-3 in this region and by the substitution of a serine residue in the sequence of PTP NE-3 for the methionine previously identified in LAR as the initiating methionine. The initiating methionine originally indicated for LAR (Streuli et al., 1988) was apparently selected because it is a better match to the consensus Kozak sequence than the upstream methionine.

\section{PTP NE-3 Is a Phosphotyrosine-Specific Phosphatase}

To determine whether PTP NE-3 is an enzymatically active PTP, the putative cytoplasmic domain from amino acid 915 to the carboxyl terminus was cloned into the expression vector PGX-KG (Guan and Dixon, 1991). A fusion protein composed of glutathione S-transferase at the amino terminus of the PTP NE-3 cytoplasmic domain was expressed in Escherichia coli and isolated on glutathione-derivatized agarose. The cytoplasmic domain of PTP N[-3 was cleaved from the glutathione S-transferase by incubation of the agarose with thrombin, which cuts the fusion protein at a site adjacent to the carboxyl terminus of the glutathione S-transferase. The purified PTP NE-3 was isolated by centrifugation of the agarose and collection of the supernatant. PTP NE-3 remained stable in solution for at least 2 weeks at $4^{\circ} \mathrm{C}$.

Initial analysis of phosphatase activity was performed with the artificial substrate, para-nitrophenylphosphate (pNPP). The pH optimum of PTP NE-3 dephosphorylation of $\mathrm{pNPP}$ was determined to be approximately 5.6 (Figure 3). This is similar to the $\mathrm{pH}$ optimum of 5.0 reported for the PTP LAR (Pot et al., 1991). Characteristic of PTPs, the activity of PTP NF-3 on pNPP was virtually eliminated by $1 \mathrm{mM}$ vanadate (Figure $4 \mathrm{~A}$ ). Tyrosine-phosphorylated casein was dephosphorylated by PTP NE-3, but serine-phosphorylated casein was unaffected under comparable conditions (Figure 4B). Michaelis-Menton analysis of PTP NE-3 enzyme activity with the substrate $\mathrm{pNPP}$ revealed a $\mathrm{K}_{\mathrm{m}}$ of 1.5 $\mathrm{mM}$ (Figure 5). A kcat value of $1.21 \mathrm{~s}^{-1}$ was obtained estimating the PTP NE-3 protein at $75 \%$ purity based upon polyacrylamide gel electrophoresis analysis and Coomassie staining (data not shown).

\section{Tissue Distribution of PTP NE-3}

A probe extending from the first $\mathrm{FN}-\mathrm{III}$ domain to the start of the internal PTP domain was used to determine PTP NE-3 mRNA expression in various rat tissues. Northern analysis revealed that PTP NE-3 has two messages of approximately 6.75 and $5.6 \mathrm{~kb}$ (Figure 6). The smaller message is in close agreement with the 5485 bp clone isolated for PTP NE-3. The larger form was detected at low levels in heart, lung, and testes. The smaller form of PTP NE-3 was detected at high levels exclusively in brain and olfactory neuroepithelium. Southern blot analysis using a PTP NE-3 radiolabeled 
GTGGGTCCTGTGGGGCTCTTCCTTGTACTGCTGGCCAGAGGTGCTTGGCT GAAGAGCCACCCAGATTTATCAGAGAGCCCAAGGATCAGATTGGTGTGTCAGGAGGCGHGGCCTCCTTCGTGTGCCAGCCCAC

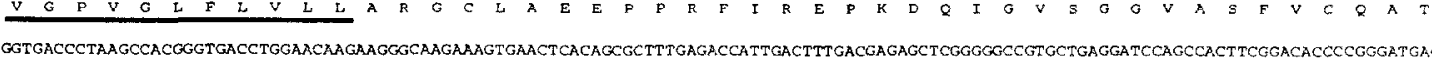

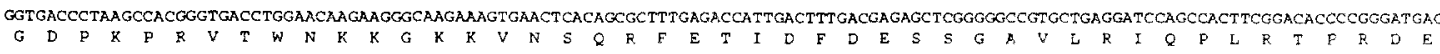
AACGTGTACGAGTGTGTGGCCCAGAACTCGGTGGGGGAGATCACAGTTCATGCGAAGCTCACCGTCCTGCGAGAGGACCAGCTGCCTCCTGGCTTCCCCAACATT TGACATGGGCCCCCAGTTGZAGGTTGTAGAG $N$ V CGCACACGCACAGCCACCATGCTCTGTGCTGCCAGCGGAAACCCTGACCCTGAGATCACCTGGTTCAAGGACTTCCTGCCTGTGGACCCCAGTGCCAGCAATGGGCGGATCAAGCAGCTTCGGTCAGGTGCCCT $\begin{array}{llllllllllllllllllllllllllllllllllllllllllllll}R & T & R & T & A & T & M & L & C & A & A & S & G & N & P & D & F & E & I & T & W & F & K & D & F & L & P & V & D & F & S & A & S & N & G & R & I & K & Q & L & R & S & G & A & L\end{array}$

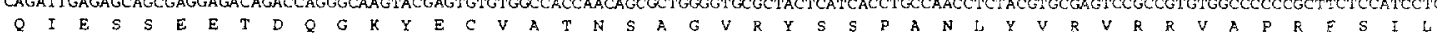
CCCATGAGCCACGAGATCATGCCCGGTGGGATGTGAgTATCACTTGTGTGGCTGTGGGCTCACCCATGCCCTACGTGAaGTGGATGCAGGGGGCAGAGGACCTGACGCCTGAGGATGACATGCCCGTGGGTCGO

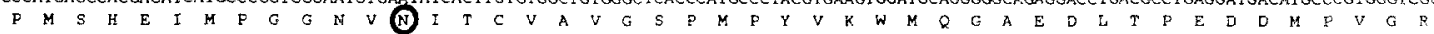

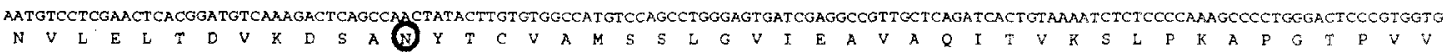
CGCTACAGCATCGGCGGCCTGAGCCCCAACTCTGAGTATGAGATCTGGGTGTCAGCTGTCAACTCCATCGGCCAGGOCCCCCCCCAGTGRGTCGGTGGTGACCCGCACAGGCGAGCAGGCACCAGCCAGTGCTCCC $134 \mathrm{O}$

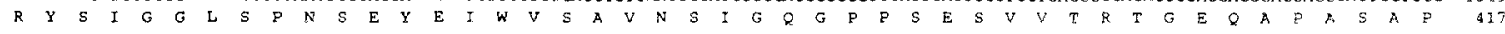
AGGAATGTTCAGGCGCGCATGCTCAGTGCCACOACCATGATTGTGCAGTGGGAGGAGCCCGTGGAGCCCAATCGCCTGATCCGTGGCTACCGCGTCTACTACACCATGGAGCCCGAGCATCCGGTGGGCA.ACTGG 1.484

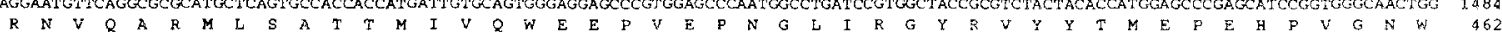
CAGAGGCACAATGTGGACGACAGTCTTCTGACCACTGTGGGCAGCCTGCTAGAGGATGAGACCTACACTGTGAGAGTGCTCGCCTTCACATCGGTGGGCGATGGGCCACTGTCAGACCCCATCCAGGTCAAGACC 1619 Q $\quad$ K CAGCAGGGAGTGCCCGGCAGCCCATGAACTTGCGGGCTGAGGCCAAGTCAGAGACCAGCATTGGGCTCTCGTGGAGTGCACCACGGCAGGAGAGTGCATTAAGTATGAACTGCTCTTCCGGGAGGGCGACCGA 1754

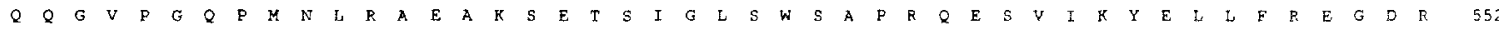
GGCCGAGAGGTGGGGCGARCCTTCGACCCAACCACAGCCTTTGTGGTGGAGGACETCAAGCCCAATACGGAGTACGCGTTCCGGCTGGCGGCTCGCTCGCCGCAGOGCCTGGGCGCCTTCACCGCGGTIGTGTGC 1289

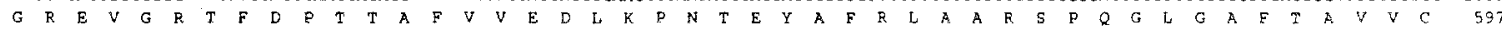
CACCGCACACTGCAGGCCATCTCCCCCANGAACTITCAGGTGAAGATGATCATGAARACTTCAGTGCTCCTAAGCTGGGAGTTCCCTGACAACTATAACTCACCCACGCCCTACAAGATCCAGTZCOATGCACTC 2024

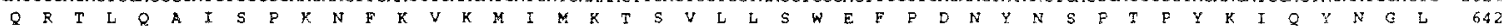
ACACTGGACGTGGATGGCCGCACTACCAAGAAGCTGATCACGCACCTCAMGCCACACACCTTCTATAACTTCGTGCTCACCAACCGTGGCAGCAGCCIGGGAGGCCTGCAGCAGACGGTCACCGCCAGGACCGCC ZI 59 T L TTCAACATGCTCAGTGCCAAGCCTAGTGTCGCCCCAAGCCTGACAACGATGGTTCCATTGTGGTCTACCTGCCTGATGGCCAGAGTCCCGTGACAGTGCAGAACTACTTCATTGTGATGGTCCCACTTCGGAAG ZZ 24

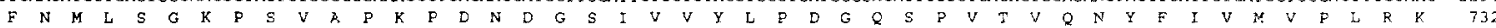
TCTCGTGGTGGCCAGTTCCCTATCCTACTAGGTAGTCCAGAGGACATGGATCTGGAGGAGCTCATCCAGGACCTCTCCCGGCTGCAGAGGCGCAGCCTGCGCCACTCAAGACAGCTGGAGGTGCCTCGGCCTTAC 2429 $S$ R G G Q ATCGCCGCTCGGTTCTCCATCCTGCCAGCTGTCTTCCATCCTGGGAACCAGAAGCAATATGGTGGTTTGACAACAGGGQCTTGGAGCCAGGCCACCGTTATGTCCTCTT TGTACT TGCTGTGCTECAGAAGAAT 25 G4

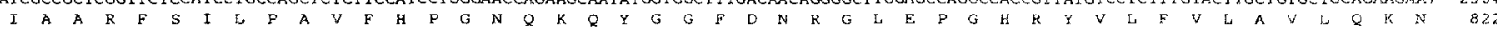
GAGCCTACATTTGCAGCCAGTCCCTTCTCP.CACCCCTTCCAACTGGACAACCAGACCCGCAGCCCATTCTGGATGGCGAGGAGGCCTCATCTGGGEATCGECCCCGTGCTGGCCGTGGTCTTCATCATCTGC 2699

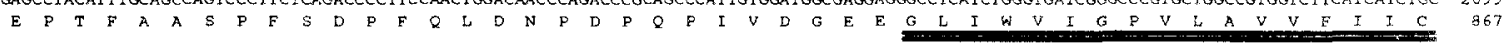
ATCGTAATTGCCATCCTGCTGTACAAGAACAAGCCTGACAGCAAACGCAAGGACTCAGAGCCCCGCACCAAATGCTTATTGAACAATGCAGACCTCCCCCCCCATCACCCCAAGGACCCTGTGGAAMTGCGACGT 2834

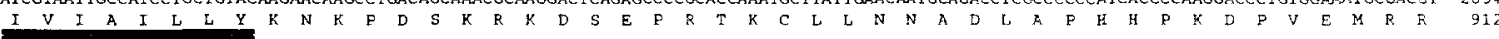

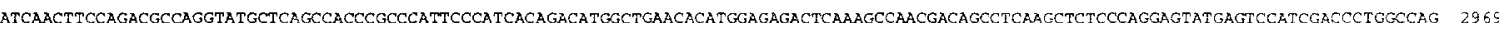

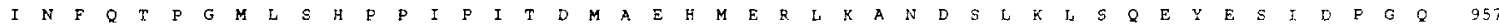
CAGTTCACTTGGGAACATTCGAACCTGGAGGCCAACAAGCCAAAGAACCGATACGCCAATGTCATCGCCTATGACCATTCACGAGTCATCCTGCAGCCTMTIAGAAGGCATCATGGGTAGTGATTMCRTCMATGCO 3104

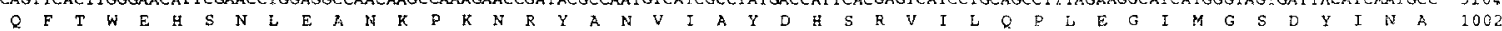
AACTATGTGGACGGCTATCGGCGGCAGAACGCATACATCGCCACGCAGGGGCCCCTGCCTGAGACCTTTGGGGACTTCTGGCGGATGGTGTGGCAGCAGCOGTCAGCCACTGTGGTCATGATGACACGGCTGGAG 3239 $\begin{array}{lllllllllllllllllllllllllllllllllllllllllllllll}N & Y & V & D & G & Y & R & R & Q & N & A & Y & I & A & T & Q & G & P & L & F & E & T & F & G & D & F & W & R & M & V & G & E & Q & R & S & A & T & V & V & M & M & T & R & E & E & 1047\end{array}$

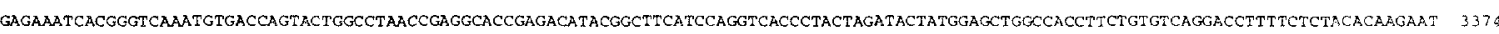

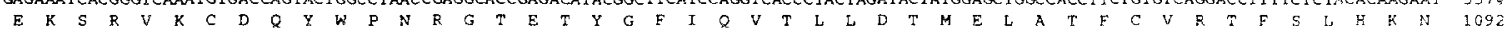
GGCTCTAGTGAGAAGCGTGAGGTACGACATTTTCAGTTCACAGCATGGCCTGACCACGGGCTACCCGAGTACCCCACACCCTTCCTGGCGTTTCTGCGCAGAGTCAAGACCTGCAACCCGCCTGACGCTGGCCCA 3509

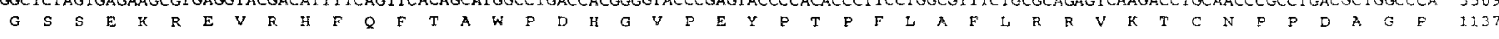
GTTGTGGTCCACTGCAGCGCGGGTGTGGGGCGTACTGGCTGCTTCATTGTAATTGATGCCATGTTGGAGCGCATCAGAACAGAGAAGACGGTGGATGTGTACGGACACGTGACACTCATGCGGTCACAGCGCAAC 3644

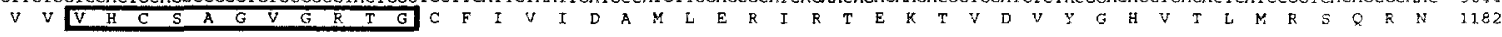
TACATGGTCCAGACAGAGGATCAGTATACCTTCATCCACGAGGCACTGCTGGAGGCTGTGGCCTGTGGCAATACCGAGGTCCCCGCGCCCAGCCTCTACACCTATATCCAGAAGCTGGCCCAGGTGGAGCCTGGC 3779

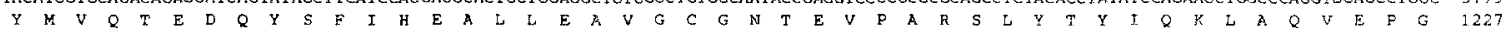
GAGCATGTCACAGGAATGGAGCTTGAGTTCAAGAGGCTTGCCAGCTCCAAGGCACACACTTCGAGATTCATCACTGCCAGCCTGCCTTGCAACMGTTTAAGAACCGCCTGGTGAACATCCTGCCGTACGAGAGC 39I 4

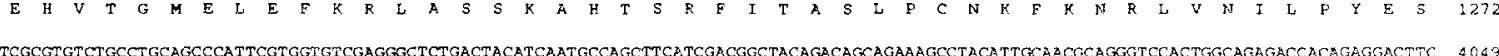

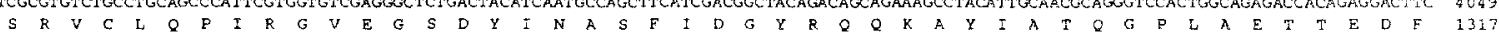
TGGCGTGCCCTGTGGGAGAACAACTCCACTATTGTGGTAATGCTCACCAAGCTCCGCGAGATGGGCCGGGAGAGTGCCACCAGTACTGGCCAGCTGAGCGCTCTGCCCGCTACCAGTACTTTGTGGTTGACCCG 4186 $\begin{array}{llllllllllllllllllllllllllllllllllllllllllllll}W & R & A & L & W & E & N & N & S & T & I & V & V & M & L & T & K & \text { I } & R & E & M & G & R & E & K & C & H & Q & Y & W & P & A & E & R & S & A & R & Y & Q & Y & F & V & V & D & P & 1362\end{array}$ STCCCACACTATAACATCCCNCACTACATTCTCCGTCACTTTAACGTCACACATGCCCGGCATGGCCACTCCCGGACCGTCCCACAGTTCCACTTCRCGGACTGGCCACAGCAGGGTGCACCChACTCAGGEGAA $43 i \mathrm{I}$

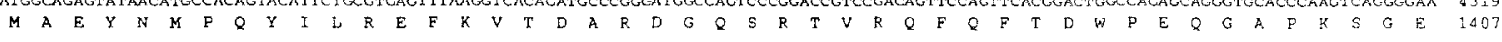
GGCTTCATTGACTRCATCGGCCAACTGCATAAGACCAAGGAGCAGTTTGGCCAGGATGGCCCCATCTCGGTGCACTGTAGTGCTGGAGTGGGCAGGACCGGAGTATTCATCACTCTGAGCATCGTGCTGGAGCGA. 4454

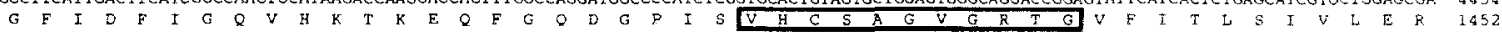
ATGCOCTACGAGGGGGTGGTGGACATTTTCCAGACAGTGAAGGTGCTTCGGACCCAGCGGCCTOCCATGGTGCAGACAGAGGATGAGTACCAGTTCTGCTTCCAGGCGGCGTTGGAATACCTGGGCAGCTTTGRT 4589

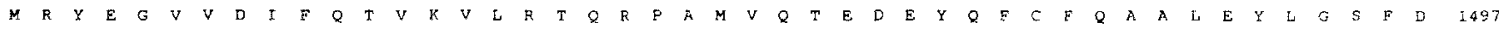
CATTATGCAACATARGCCATGGGCCCCGCCCAACACCTCGACCCAGCTCCAAGTGCCCTGATGTGAGCCCAGCCCTCGGTOCTGGGTGGGAGGCGGCCCAGGGRGGAAACCTCCTCTCCCTGGAGACACCCACT 4 724

Figure 1. The cDNA Sequence of PTP NE-3

The deduced amino acid sequence is shown below the nucleotide sequence. The putative signal sequence is underlined once (Gierasch, 1989; von Heijne, 1990). Potential N-glycosylation sites are circled. The putative transmembrane domain is underlined twice and was delermined based upon a hydrophobicity plot (data not shown). The putative active sites for each of the phosphatase domains are boxed. 


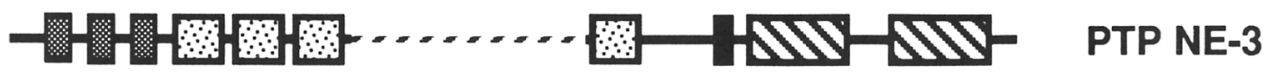

B

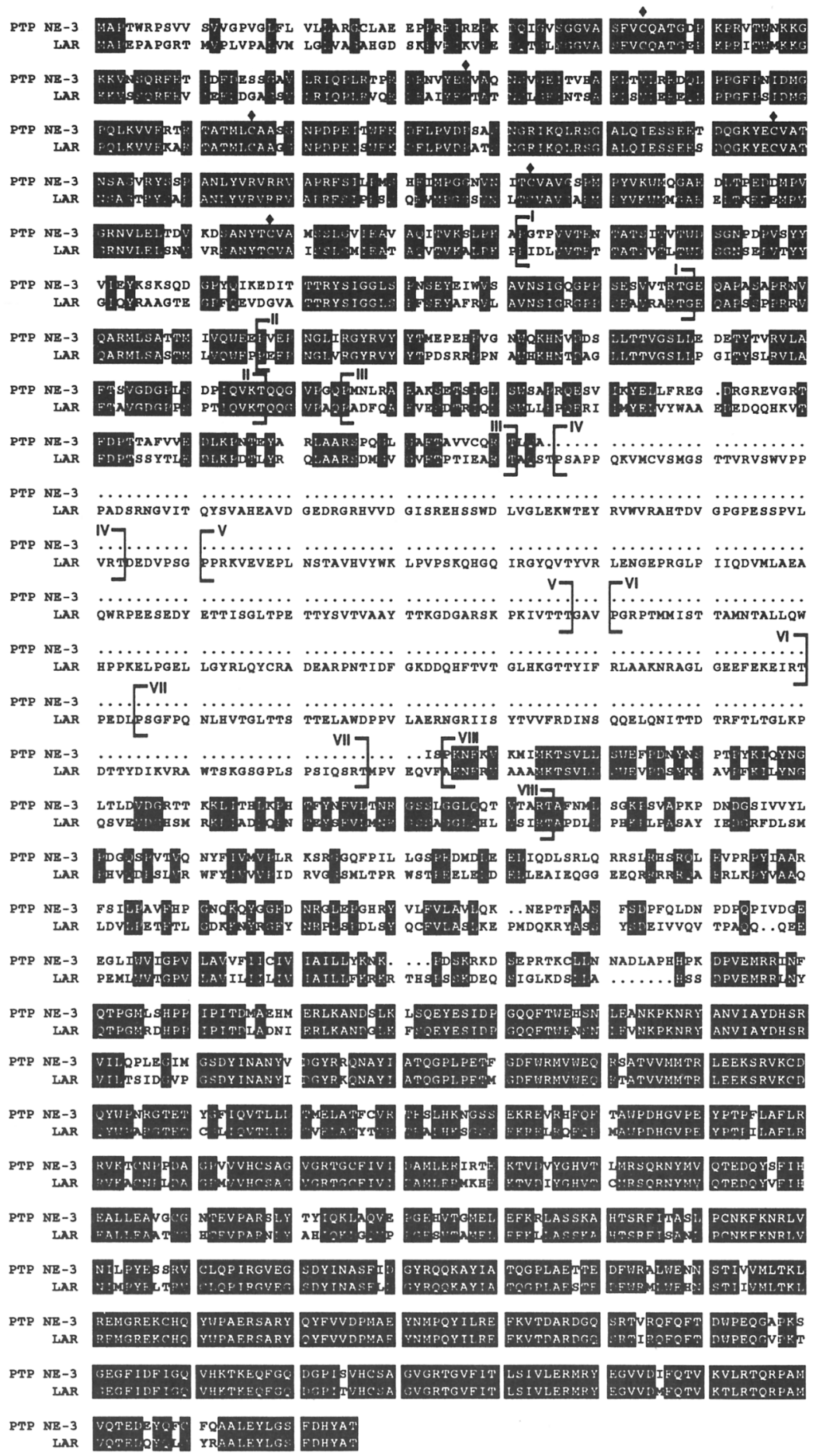

Figure 2. The PTP NE-3 Protein Sequence Is Similar to the Human Tyrosine Phosphatase, LAR

(A) Schematic of structural domains determined by sequence similarity: immunoglobulin-like domains (Williams and Barclay, 1988), densely stippled boxes; FN-III-like domains (Patthy, 1990), lightly stippled boxes; transmembrane domain, solid boxes; phosphatase domains, cross-hatched boxes. (B) Identical amino acids are shown in black. The diamonds indicate conserved cysteine residues in the immunoglobulin-like domains; the brackets denote the individual FN-III-like domains. The indicated initiating methionine of LAR differs from the previously published sequence (Streuli et al., 1988). 


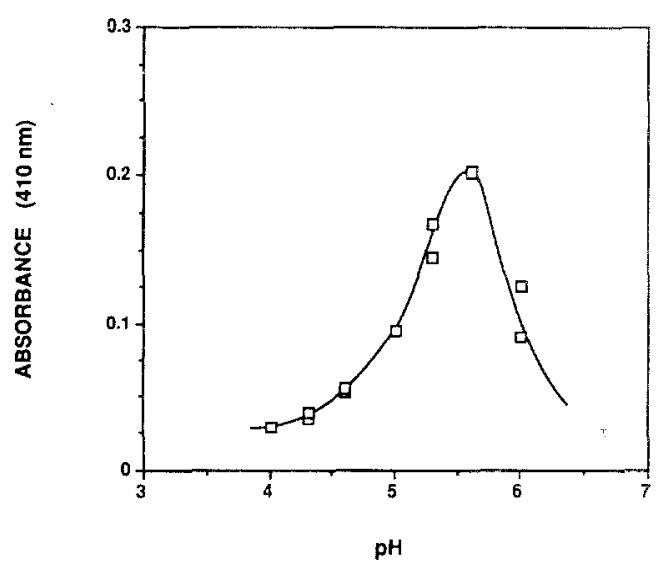

Figure 3. $\mathrm{pH}$ Optimum of PTP NE-3 on pNPP

The activity of PTP NE-3 was determined at the indicated $\mathrm{pH}$ values in $100 \mathrm{mM}$ imidazole buffer, using $3.5 \mu \mathrm{g}$ of protein incubated for $10 \mathrm{~min}$.

A

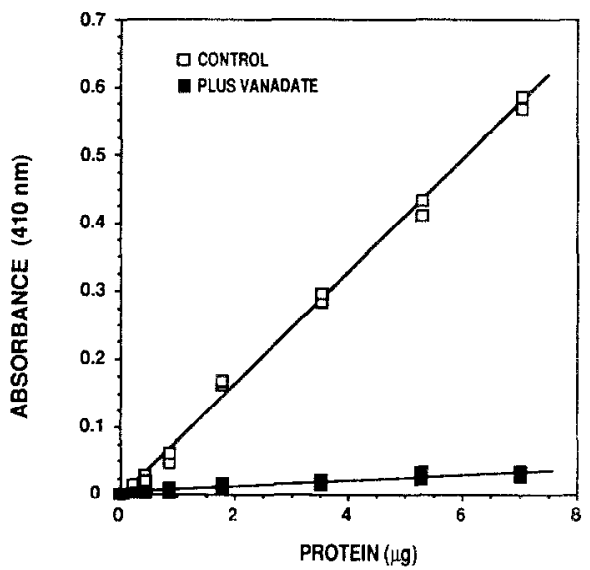

B

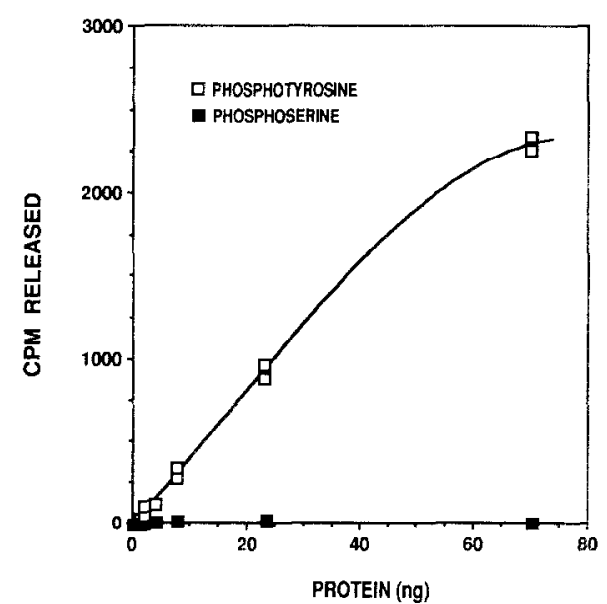

Figure 4. PTPNE-3 Phosphatase Activity Is Inhibited by Vanadate and is Specific for Phosphotyrosine

(A) Phosphatase activity of PTP NE-3 on pNPP was determined at $\mathrm{pH} 5.6$ in the presence or absence of $1 \mathrm{mM}$ sodium vanadate. (B) Phosphatase activity at $\mathrm{pH} 7.0$ of PTP NE-3 on casein phosphorylated on either tyrosine or serine by the kinases $\mathrm{v}$-SrC and protein kinase $\mathrm{A}$, respectively.

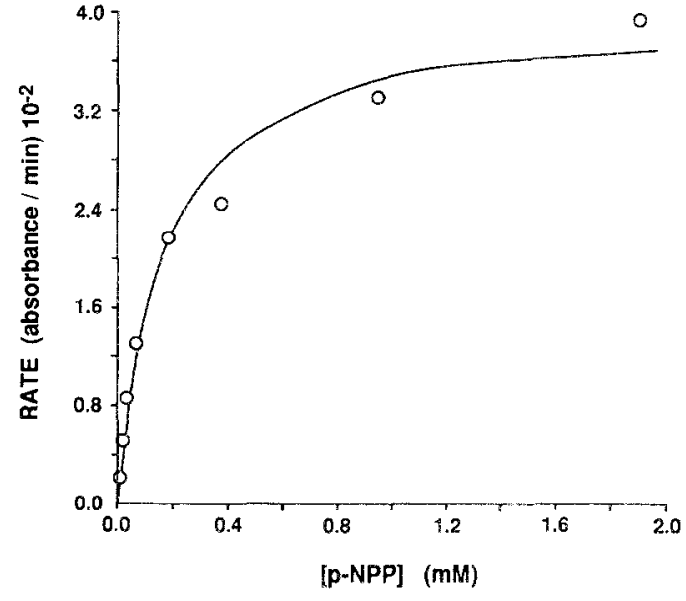

Figure 5. Kinetic Analysis of PTP NE-3 on pNPP

The activity of PTP NE-3 was determined on the indicated amounts of $\mathrm{PNPP}$ in $100 \mathrm{mM}$ imidazole buffer at $\mathrm{pH} 5.6$.

probe (5290 bp cDNA) demonstrated hybridization patterns (with non- and single-cutting restriction enzymes) consistent with the existence of a single gene for PTP NE-3, suggesting that the two RNA species represent alternatively spliced variants and/or have alternative polyadenylation sites (data not shown). The alignment of PTP NE-3 with LAR suggests a possible location for an alternative splice, i.e., the absent FN-III domains. Recently, a longer form of PTP NF-3 that does include three of these missing FN-III domains was cloned from rat liver (B. Goldstein, personal communication). This longer form likely represents the larger sized message identified in our Northern blots.

\section{In Situ Hybridization Histochemistry Analysis of PTP NE-3 Expression}

The neural tissues identified by Northern blot analysis as having high levels of PTP NE-3 expression were examined by in situ hybridization histochemistry to determine the cellular pattern of cxpression. $\wedge$ high level of expression was observed in the hippocampal pyramidal cells and dentate gyrus of adult rat brain (Figure 7). Lower levels of expression in the cortex, thalamus, and granule cell layer of the cerebellum were also detected. No signal was detected in the neuronal tracts, suggesting that expression of PTP NE-3 in the brain is limited to neurons.

In adult rat olfactory neuroepithelium, in situ hybridization histochemistry (utilizing colorimetric visualization) of PTP NE-3 message demonstrated a neuron-specific pattern of expression (Figure 8). Digoxigenin-labeled riboprobes were also used for the growth-associated protein GAP-43 and olfactory marker protein (OMP), as they represent specific markers for the immature and mature populations of neurons in the olfactory neuroepithelium, respectively (Margolis, 1985; Verhaagen et al., 1989, 1990). GAP-43 expression is limited to the neuronal precur- 
A

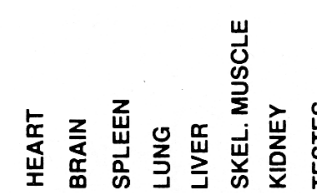

$9.5-$
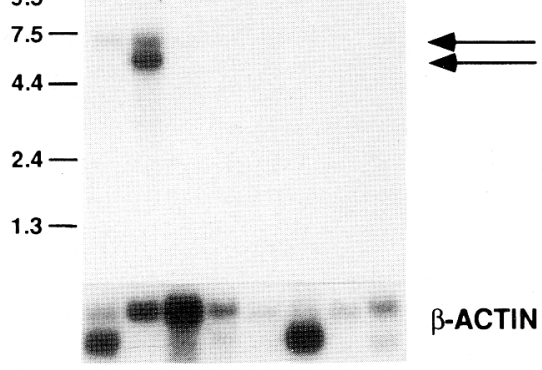

B

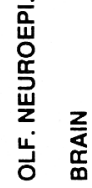

$18 \mathrm{~S}$

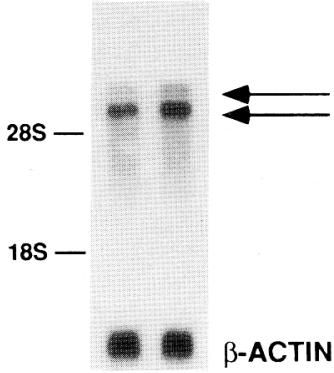

Figure 6. Tissue-Specific Expression of PTP NE-3 mRNA

Northern analysis of PTP NE-3 mRNA expression in the indicated rat tissues. Samples of $\operatorname{poly}(\mathrm{A})^{+} \mathrm{mRNA}(2 \mu \mathrm{g})$ from the indicated tissues were separated by denaturing gel electrophoresis and transferred to a nylon membrane (Nytran, Schleicher \& Schuell). The blot was hybridized to radiolabeled probes to PTP NE-3 and $\beta$-actin under high stringency (see Experimental Procedures) and washed under high stringency $\left(0.2 \times \mathrm{SSC}, 0.1 \% \mathrm{SDS}, 65^{\circ} \mathrm{C}\right)$. The control hybridization to $\beta$-actin mRNA demonstrates that relatively equal amounts of RNA were electrophoresed from each rat tissue, since the observed hybridization signal compared favorably to expected levels for each tissuc. In $(\Lambda)$, the size markers refer to size in kilobases; in (B), the size markers show the mobility of the indicated rRNA. sors positioned immediately apical to the undifferentiated basal cells and subjacent to the mature, functioning sensory neurons. OMP expression is restricted to the mature sensory neurons and does not overlap with GAP-43 (Margolis, 1985; Verhaagen et al., 1989, 1990). PTP NE-3 has a unique pattern of expression that overlaps with both GAP-43 and OMP. PTP $\mathrm{NE}-3$ is expressed strongly in the cell layer immediately apical to the basal cells, identified as the immature, GAP-43-positive neurons. However, unlike GAP-43, PTP NE-3 is also expressed in the mature, OMP-positive neurons. Close analysis of the histo- chemical staining indicates that PTP NE-3 may be expressed in a gradient, with expression higher in the neuronal precursors and lower in the mature sensory neurons. In further support of the neuronal specificity of PTP NE-3, expression of the phosphatase, as with OMP, is lost upon transition of the olfactory neuroepithelium to respiratory epithelium (Figure 9).

\section{Discussion}

Noting the importance of tyrosine phosphorylation in the control of ncuronal cell development and func-

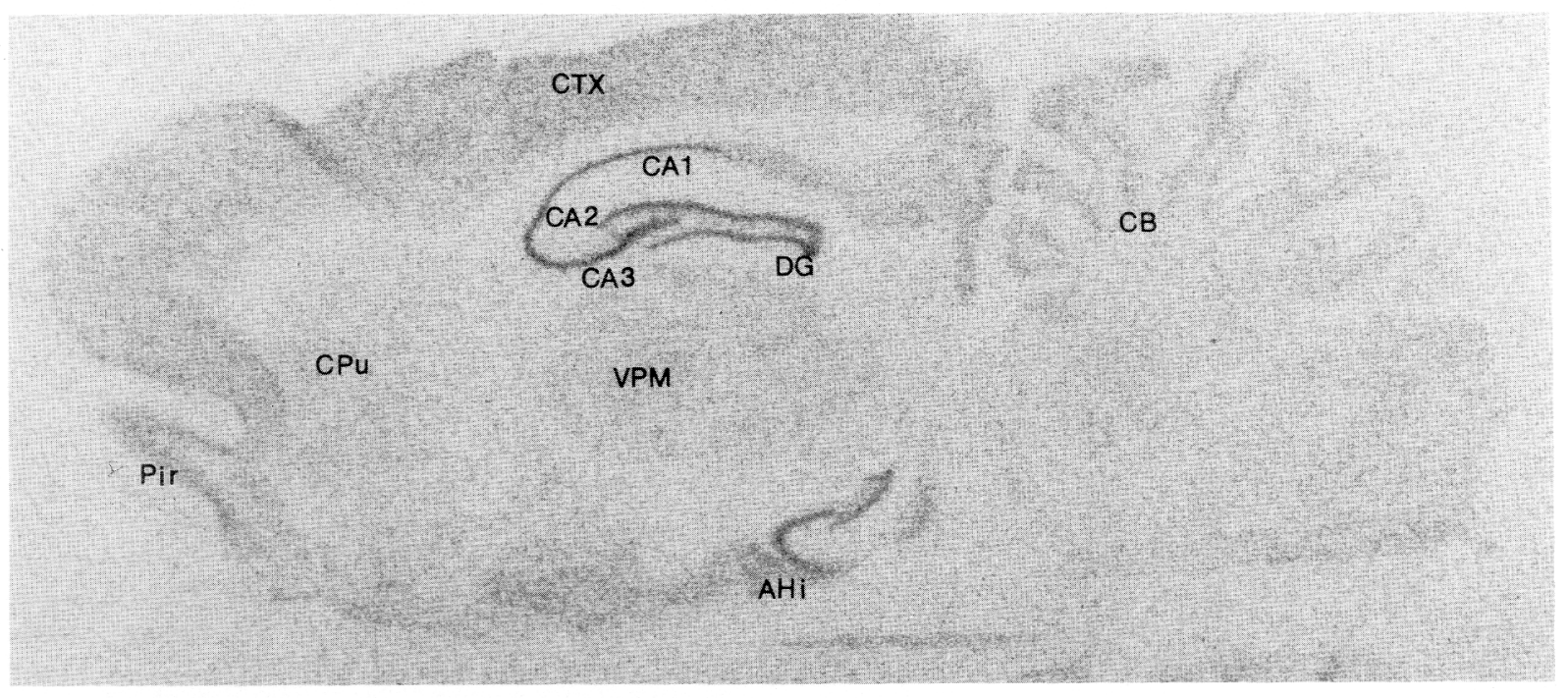

Figure 7. PTP NE-3 mRNA Is Expressed at High Levels in the Hippocampal Formation of Rat Brain

In situ hybridization histochemistry of PTP NE-3 mRNA expression was determined by hybridization of a rat brain cryosection with a radiolabeled antisense riboprobe to PTP NE-3. Note high expression levels in the pyramidal cells of the hippocampus and the dentate gyrus. The section was exposed to Kodak X-AR film for 3 days. An equivalently prepared and hybridized sense control probe gives a completely blank hybridization signal. AHi, amygdaloid hippocampal area; CA1, CA2, and CA3, pyramidal cells of the hippocampus; $\mathrm{CB}$, cerebellum; CPu, caudate putamen; CTX, cerebral cortex; DG, dentate gyrus; Pir, piriform cortex; VPM, ventral posterior medial nucleus of the thalamus. 

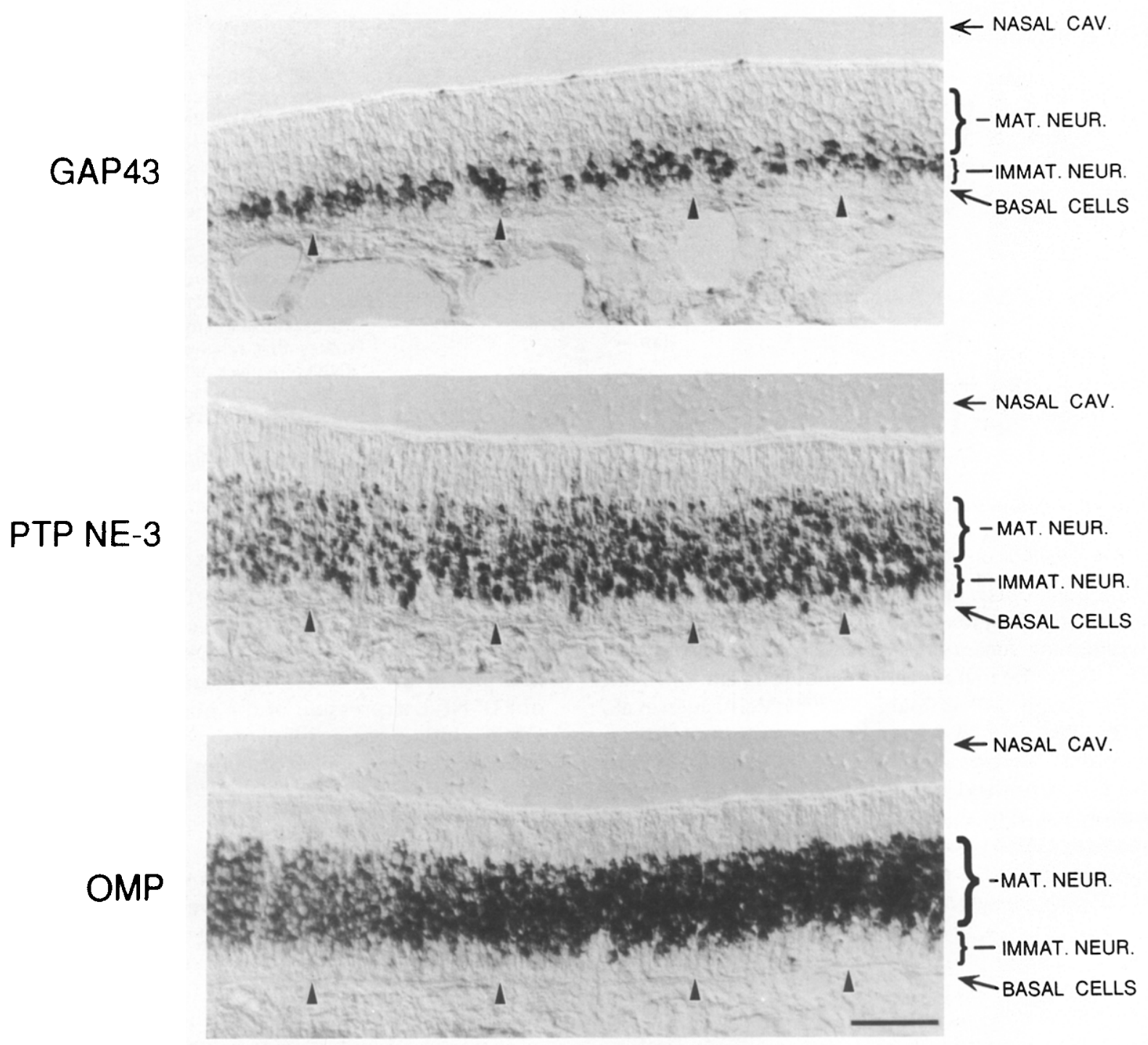

Figure 8. In the Olfactory Neuroepithelium, PTP NE-3 mRNA Is Expressed Only in the Neuronal Lineage

In situ hybridization histochemistry of PTP NE-3 mRNA expression was determined by hybridization of a $10 \mu \mathrm{m}$ cryosection of rat olfactory neuroepithelium with a digoxigenin-labeled antisense riboprobe to PTP NE-3. Hybridized probe was detected with alkaline phosphatase-conjugated antibodies to digoxigenin, with subsequent color development with NBT/X-phosphate. Control in situ hybridization probes for GAP-43 and OMP are shown to demonstrate populations of immature neurons and mature sensory neurons, respectively. Labeled arrows and brackets indicate the nasal cavity, mature neurons, immature neurons, and basal cells. Arrowheads within the photomicrographs indicate the basal limit of the neuroepithelium in al! three panels. Note that PTP NE-3 demonstrates expression overlapping both populations of neuronal cells, with higher expression in the immature neurons. Expression of GA.P-43 and PTP NE-3 begins $0-1$ cell body widths directly apical of the basal cells lying at the basal lamina, whereas OMP expression usually begins an additional 1-2 cell body widths apically. An equivalently prepared and hybridized sense control probe gives a completely blank hybridization signal. The photomicrograph was taken under Nomarski optics. Bar, $50 \mu \mathrm{m}$.

tion, we examined the olfactory neuroepithelium for the expression of novel PTPs that may play a role in the persistent neurogenesis displayed by the olfactory neuroepithelium. We have identified a receptor-type phosphatase, PTP NE-3, which is clearly enriched in neural tissue and displays an alternatively spliced form that appears to be neuron specific. PTP NE-3 has two cytoplasmic phosphatase domains, common to receptor-type PTPs. The phosphatase activity of PTP NE-3 appears specific for phosphotyrosine with no activity on phosphoserine. Kinetic analysis determined a kcat value of $1.21 \mathrm{~s}^{-1}$ for PTP NE-3, within the midrange of activity for PTPS. For example, the related PTP, LAR, has a kcat value of $6.1 \mathrm{~s}{ }^{1}$ (Pot et al., 1991), while cdc25 and the bacterial PTP, YOPH, have kcat values of $0.033 \mathrm{~s}^{-1}$ and $1234 \mathrm{~s}^{-1}$, respectively (Dumphy and Kumagai, 1991; Zhang et al., 1992). The $K_{m}$ of PTP NE-3 for pNPP, $1.5 \mathrm{mM}$, is similar to those for other PTPs: e.g., LAR, $0.4 \mathrm{mM}$; PTP 1C, $1.5 \mathrm{mM}$; and YPTP1, $1.2 \mathrm{mM}$ (Pot et al., 1991; Zhao et a!., 1993; Zhang et al., 1992).

In the olfactory neuroepithelium, PTP NE-3 is ex- 

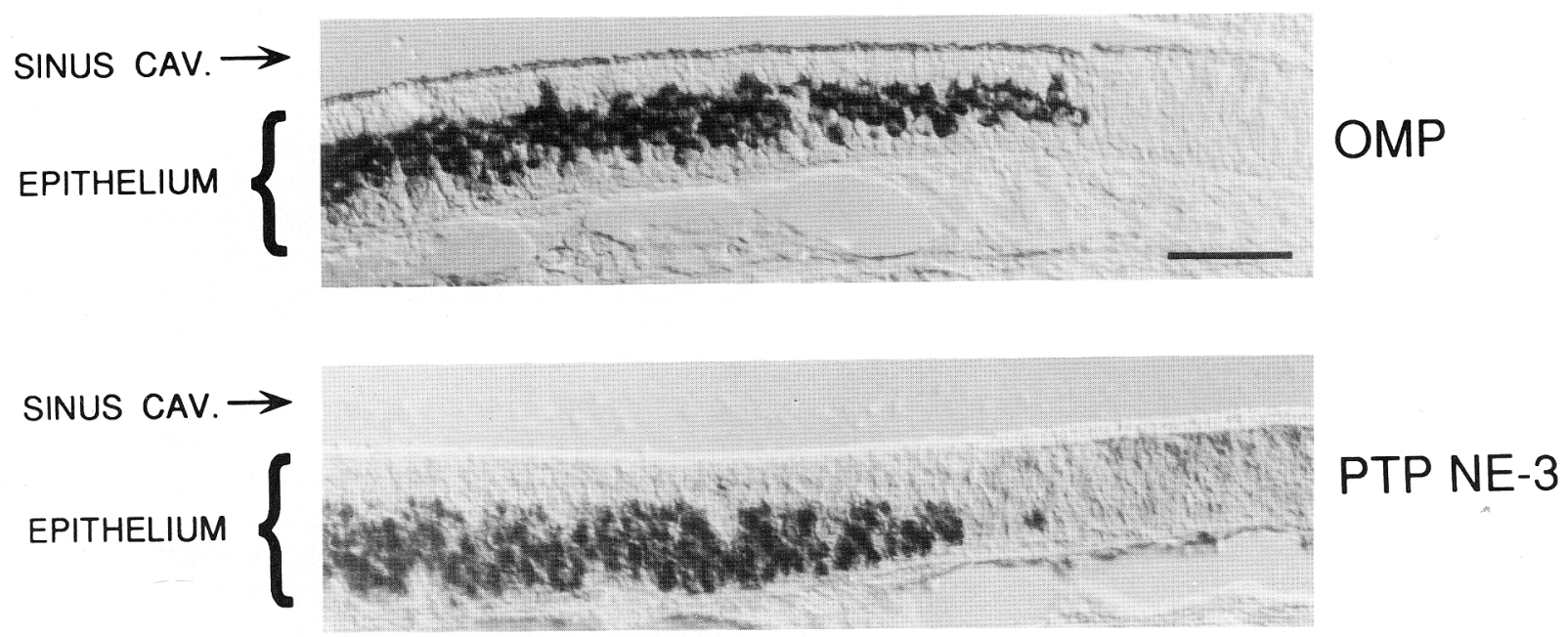

Figure 9. Expression of PTP NE-3 in the Nasal Epithelium Is Lost upon Transition from Olfactory Neuroepithelium to Respiratory Epithelium

In situ hybridization histochemistry of PTP NE-3 mRNA expression was determined by hybridization of a $10 \mu \mathrm{m}$ cryosection of rat olfactory neuroepithelium with a digoxigenin-labeled antisense riboprobe to PTP NE-3. Hybridized probe was detected with alkaline phosphatase-conjugated antibodies to digoxigenin, with subsequent color development with NBT/X-phosphate. In situ hybridization histochemistry of OMP mRNA expression is shown as a control indicating the population of mature olfactory sensory neurons. At the transition of olfactory neuroepithelium to respiratory epithelium, the expression of OMP and PTP NE-3 ceases, since respiratory epithelium is devoid of olfactory neurons. These photomicrographs clearly indicate the earlier expression of PTP NE- 3 relative to OMP within the olfactory neuronal lineage. The photomicrograph was taken under Nomarski optics. Bar, $50 \mu \mathrm{m}$.

pressed only in the olfactory neuronal lineage (Figures 8 and 9). Furthermore, PTP NE-3 is expressed by the neurons in a unique, developmentally regulated manner. Like GAP-43, PTP NE-3 is detected at high levels in the population of neuronal precursors but does not appear to be expressed in the basal cell population. While clcarly not expressed in the horizontal basal cell population, at present we cannot rule out possible PTP NE-3 expression in the globose basal cells that are believed to be the principal source of olfactory neuronal precursors under normal neurogenesis conditions (Schwartz Levey et al., 1991; Schwob et al., 1992). However, unlike GAP-43, PTP NE-3 is also expressed in mature, OMP-positive neurons. The continued expression of PTP NE-3 in mature neurons suggests a functional role in these sensory neurons in addition to any putative developmental role. Alternatively, the persistent expression of PTP NE-3 in OMPpositive neurons, albeit at an apparently lower level, may reflect simply the relatively immature state of olfactory sensory neurons compared with adult mammalian neurons. Mature olfactory neurons, perhaps as a reflection of their developmental and synaptic plasticity, continue to express various genes that are typical of immature, developing neural cells, including the embryonic form of the neural cell adhesion molecule N-CAM (E-N-CAM), vimentin, microtubuleassociated proteins MAP2C and MAP5a, and juvenile tau (Miragall et al., 1988; Viereck et al., 1989; Schwob et al., 1990).

While PTP NE-3 is expressed in a number of brain areas, the highest expression level is observed in the hippocampal formation, most likely the pyramidal cells. Interestingly, the hippocampus is a region of the brain strongly associated with plasticity, particularly in relation to learning and memory, and exhibits some of the highest levels of CNS GAP-43 expression, a landmark for synaptic plasticity (Benowitz et al., 1988; Neve et al., 1988; De La Monte et al., 1989; Ramakers et al., 1992). Likewise, the adult mammalian olfactory system represents a robust model for synaptic plasticity in a neural tissue and, indeed, exhibits high levels of GAP-43 and PTP NE-3 expression. The CNS nerve tracts, which contain glial cell bodies but essentially no neuronal cell bodies, did not contain any PTP NE-3-positive cells. This reinforces the idea that this PTP is selectively, or perhaps exclusively, expressed in neuronal populations.

PTP NE-3 is most closely related to the human PTP LAR. An amino acid alignment with LAR reveals that both clones have three immunoglobulin-like domains within the putative extracellular region at the amino terminus. Indicative of these domains is a pair of cysteine residues, thought to form disulfide bridges within each immunoglobulin-like domain, which are conserved in PTP NE-3. LAR also has eight FN-IIl domains. However, PTP NE-3 has only four of these domains, aligning with domains I, II, III, and VIII of LAR. The role of the immunoglobulin-like and FN-III domains in these phosphatases is unknown. However, they are present in cell adhesion molecules like N-CAM and myelin-associated glycoprotein (Cunningham et al., 1987; Lai et al., 1987). Some of these factors, such as $\mathrm{N}$-CAM, bind in a homophilic manner (Rutishauser 
and Jessell, 1988). While N-CAM has five immunoglobulin-like domains, only the two most amino-terminal repeats are involved in the binding (Williams and Barclay, 1988). Other proteins in this immunoglobulin superfamily of cell adhesion molecules, the I-CAMs, bind to integrin receptors on adjacent cells (Staunton et al., 1988; Elices et al., 1990). This interaction is in volved in the movement of neutrophils through the endothelial cells that line the blood vessel wall. Furthermore, the migration of neurons in developing rat cerebellum is linked to the expression of another adhesion molecule with immunoglobulin-like domains, Ng-CAM (Lindner et al., 1983; Chuong et al., 1987). In the olfactory system, the process of neurogenesis involves the migration of the maturing neuronal cell body upward from the stem cell layer to roughly the middle third of the pseudostratified epithelium. Clearly, a possible role of PTP NE-3 could involve the migration of the neuronal cell body apically through the epithelium.

During neurogenesis, sensory neurons also extend dendrites to the surface of the epithelium and axons through thc base of the epithelium, where they fasciculate as the olfactory nerve and ultimately synapse within the olfactory bulb. The mechanisms controlling growth cone elongation and direction remain to be fully elucidated, but interactions of the growth cone with either the extracellular matrix or axon tracts appear to play important roles in this process (Grenningloh et al., 1990; Hynes and Lander, 1992). Four proteins that can function as homophilic adhesion molecules and are expressed on different overlapping subsets of growth cones and axons during embryogenesis have been identified in Drosophila (Grenningloh el al., 1990). Three of these factors, fasciclin II, fasciclin III, and neuroglian have immunoglobulin-like domains or both immunoglobulin-like and FN-III domains. These proteins continue to be expressed after the nervous system has been completely established and may function at this point to stabilize structures. In a similar manner, PTP NE-3 is expressed early during neurogenesis of olfactory neurons as well as in the mature sensory neurons, where it may serve to stabilize the neuronal architecture.

The role of tyrosine phosphorylation in growth cone pathfinding is supported by experiments involving two cytoplasmic tyrosine kinases. One of these, c-Src, is involved in the signal transduction pathway of nerve growth factor (Kremer et al., 1991). c-Src is preferentially distributed in the growth cones and proximal axon shafts in neonatal rat brain (Maness et al., 1988; Le Beau et al., 1991). In vitro experiments revealed that tyrosylphosphorylation of tubulin by c-Src inhibits tubulin's ability to polymerize into microtubules (Maness and Matten, 1990; Matten et al., 1990). Furthermore, c-Src-dependent phosphorylation of tubulin in nerve growth cones is specifically inhibited by preincubation with the extracellular fragments of various cell adhesion molecules of the immunoglobulin superfamily that promote neurite outgrowth (L1,
N-CAM, or microtubule-associated protein) (Atashi et al., 1992). These data strongly suggest there should be a dynamic interaction between tyrosine phosphatases and $\mathrm{c}-\mathrm{Src}$ to control growth cone elongation. As an example, it has been hypothesized that receptor-type protein tyrosine phosphatases with extracellular adhesion motifs might regulate c-Src activity by dephosphorylation (Yang et al., 1991; Tian et al., 1991). Additionally, PTPs could acl directly on tubulin, thus altering its ability to polymerize. Direction of growth cone movement could be controlled by dephosphorylation of tubulin on one side of the growth cone (extension) while it is being phosphorylated on the other side (retraction). An in vivo model of the role of tyrosine phosphorylation in growth cone extension has been presented using the Drosophila homolog of the Abelson tyrosine kinase, Abl. This cytoplasmic tyrosine kinase is almost exclusively localized to developing CNS axons during embryogenesis in Drosophila (Gertler et al., 1989). Deletion of either the Abl kinase or the homophilic adhesion molecule fasciclin I do not show any gross defects in neuronal development (Elkins et al., 1990). However, a double deletion of both $\mathrm{Ab}$ land fasciclin I reveals major defects in CNS axon pathways, particularly in axon tracts where the expression of these two factors normally overlaps.

The mechanism controlling the activity of PTP NE-3 is unclear. Currently, the only receptor-type PTP with its activity known to be regulated by extracellular signals is CD45, a PTP present on most cells of hematopoietic origin. Antibodies to the extracellular portion of CD45 will activate lymphocytes, and T cells deficient in cell surface CD45 are unable to respond to antigen (Pingel and Thomas, 1989). CD45 appears to function through the activation of several intracellular kinases (Trowbridge, 1991). However, the extracellular domain of $\mathrm{CD} 45$ does not have the immunoglobulin-like and FN-III domains identified in PTP NE-3 or LAR, and it is currently unknown whether binding of ligands to the extracellular domains of these PTPS stimulates or inhibits their phosphatase activities. An additional mechanism controlling the activation of PTP NE-3 may be via shedding of the extracellular portion of the molecule. The phosphatase LAR has in its extracellular domain a string of five arginines. These arginines apparently act as a site for a protease that cleaves the molecule into two portions (Streuli et al., 1992; Yu et al., 1992). However, the two domains remain associated. During Hela cell growth, a portion of the extracellular domain is shed from the cells as they reach confluence. In PTP NE-3, a pair of basic amino acids aligns with the string of 5 arginines in $L A R$, including the arginine required in $L A R$ for cleavage. This suggests that PTP NE-3 may be cleaved in a similar fashion. Shedding of the extracellular portion of the molecule may be an important mechanism in the regulation of the activity of these PTPs.

Although the function of PTP NE-3 remains unknown, it is clear that PTPs can play a centra! role in cell function, as illustrated by the role of $\mathrm{CD} 45$ in $T$ 
cell activation. Other examples include the gene for the Drosophila PTP, corkscrew, a maternal gene required for the normal determination of cell fates at the termini of the embryo (Perkins et al., 1992). Deletion of the phosphatase PTP1 in Dictyostelium results in accelerated development, whereas overexpression results in severe morphological defects following aggregation (Howard et al., 1992). Interestingly, the genes for several PTPs localize to chromosomal regions associated with tumorigenesis. For example, the gene for the PTP LAR localizes to a region deleted in some tumors of neuroectodermal origin (Jirik et al., 1992). The role of PTPS in neuronal development has yet to be determined, but results from a number of laboratories have shown that receptor-type PTPs are expressed in a developmentally regulated manner in the nervous system of Drosophila (Hariharan et al. 1991; Tian et al., 1991; Yang et al., 1991). One of these, DLAR, has both immunoglobulin-like and FN-III domains (Streuli et al., 1989). The other two, DPTP10D and DPTP99A, have only FN-III domains.

The vertebrate olfactory neuroepithelium demonstrates many aspects of neurogenesis characteristic of the nervous system during embryonic development. Many of the signals involved in establishing the nervous system are unknown. The olfactory neuroepithelium is therefore an excellent resource for identifying and characterizing the molecular and cellular elements of these processes (Largent et al., 1993). We believe that receptor-type PTPs are likely to influence neurogenesis by transducing external signals intracellularly via tyrosine dephosphorylation in neurons. The novel receptor-type protein tyrosine phosphatase PTP NE-3 is expressed in a manner indicating that it may play an instrumental role in this process.

\section{Experimental Procedures}

\section{PCR Amplification of PTPs}

Degenerate DNA oligomer primers were designed based upon conserved regions within the phosphatase domains of cDNA sequences from previously published PTPs. The sequences used were 5'-CAGTGGATCCAA(A/G)TG(C/T)(C/G)(A/C)N(C/G)A(A/G)TA (C/T)TGGCC-3' (512-fold degenerate) and 5'CTAGTCTAGACCNA(T/C)(T/A/G)CCNGC(A/G)CT(A/G)CA(A/G)TG-3' (768-fold degenerate) and included sites for the restriction enzymes BamHI and $X b a l$, respectively. First strand cDNA, prepared using RNA isolated from rat olfactory tissue and oligo(dT) primers, was used as a template for the PCR. The PCR conditions were as follows: $94^{\circ} \mathrm{C}, 1 \mathrm{~min} ; 43^{\circ} \mathrm{C}, 1 \mathrm{~min} ; 72^{\circ} \mathrm{C}, 1.5 \mathrm{~min}$; for 35 cycles. Upon analysis of the reaction products by electrophoresis in an agarose gel, no bands were visible. An aliquot of the PCR product was then subjected to a second round of PCR under the following conditions: $94^{\circ} \mathrm{C}, 1 \mathrm{~min} ; 52^{\circ} \mathrm{C}, 1 \mathrm{~min} ; 72^{\circ} \mathrm{C}, 1.5 \mathrm{~min}$; for 35 cycles. Reaction products of the expected size $(\sim 280 \mathrm{bp})$ were now visible upon electrophoresis in an agarose gel. The band was isolated, digested with the restriction enzymes BamHI and $X$ bal, and cloned into the vector $\mu B$ luescript II. The inserts were sequenced using the vector T7 and T3 primer sites.

\section{Isolation of cDNA Clones}

A rat brain cerebral cortex library (provided by $M$. Brownstein, National Institutes of Health) in the vector pCD (Okayama et al. 1987 ) was plated at a density of 25,000 colonies per $150 \mathrm{~mm}$ plate, and 375,000 clones were screened by the method of Grunstein and Hogness (1975). The PCR fragment designated PTP NE-3 was excised from pBluescript II, labeled by random priming (Sambrook et al., 1989), and used as the initial hybridization probe. A second round of screening to obtain a larger clone was performed using a $400 \mathrm{bp}$ fragment from the 5 ' end of the PTP NE-3 sequence from the initial screen. To obtain the $5^{\prime}$ end of the clone, 5' RACE (Frohman, 1990) was performed using a 5 ' RACE kit (BRL). The DNA oligomer 5'-CAAAGCGCTGTGAGTTCACT-3 was synthesized based upon the $5^{\prime}$ end of the sequence and used as a primer for cDNA synthesis from rat brain RNA. The CDNA was tailed by terminal transferase with $\mathrm{DCTP}$, and PCR was performed using a DNA oligomer complementary to the poly(dC) tail (provided in the kit) and the DNA oligomer 5'-TAG TCGACCCTCTGACACACCAATCTGAT-3', which is $5^{\prime}$ to the original oligomer used for cDNA synthesis. The product was electrophoresed in an $1 \%$ agarose gel, and the DNA band isolated, cut with the restriction enzyme Sall (designed into both of the DNA oligomer primers), and cloned into pBluescript II.

Expression of the Cytoplasmic Domain of PTP NE-3 in E. coli A BsaHI-BamHI fragment of PTP NE-3 that included coding sequence for the entire cytoplasmic domain from amino acid 915 was isolated, blunt ended using the Klenow fragment of DNA polymerase 1, and cloned into the vector pGX-KG (Guan and Dixon, 1991) that had been cut with $\mathrm{Xbal}$ and also blunt ended. This construction, pGX-PTP NE-3, was transformed into the E. coli strain BL21 (DE3), and protein was expressed and purified as described previously (Guan and Dixun, 1991). Phosphatase activity, as measured by hydrolysis of $\mathrm{pNPP}$, was determined in a 200 $\mu$ l reaction volume containing $0.1 \mathrm{M}$ sodium acetate, $0.1 \mathrm{mM}$ EDT $A$, and $0.1 \% \beta$-mercaptoethanol at the indicated $\mathrm{pH}$ and incubated at $37^{\circ} \mathrm{C}$ for $15 \mathrm{~min}$. The reaction was term inated by addition of $800 \mu$ l of $0.2 \mathrm{M} \mathrm{NaOH}$, and reaction product was determined by measurement of absorbance at $410 \mathrm{~nm}$. For determination of kcat, an extinction coefficient of $1.78 \times 10^{4} \mathrm{M}^{-1} \mathrm{~cm}^{-1}$ was used to determine the concentration of the pNPP reaction product. Substrate specificity was determined on serine- and tyrosinephosphorylated casein. Casein was phosphorylated on tyrosine by incubating $100 \mu \mathrm{g}$ of casein in $155 \mu \mathrm{l}$ of $30 \mathrm{mM}$ HEPES (pH 7.5), $30 \mu \mathrm{MATP}, 10 \mathrm{mM} \mathrm{MgCl}_{2}, 3 \mu \mathrm{m}$ EDTA, $0.6 \% \beta$-mercaptoethanol, 5 $\mu l$ of $\left[\gamma^{3}{ }^{32}\right.$ P]ATP $(7000 \mathrm{Ci} / \mathrm{mmol})$, with $0.4 \mu \mathrm{g}$ of bacterially expressed $v$-src at $30^{\circ} \mathrm{C}$ for 30 min. Casein was phosphorylated on serine by incubating $100 \mu \mathrm{g}$ of casein in $200 \mu \mathrm{l}$ of $40 \mathrm{mM}$ Tris$\mathrm{HCl}(\mathrm{pH} 7.5), 20 \mathrm{mM} \mathrm{MgCl}_{2}, 0.2 \mathrm{mM} \mathrm{ATP}, 10 \mathrm{mM}$ dithiothreitol, $5 \mu$ of [ $\gamma_{-}{ }^{32}$ P]ATP $(7000 \mathrm{Ci} / \mathrm{mmol})$, with 12.5 units of the catalytic subunit of protein kinase $A$ (Sigma) at $30^{\circ} \mathrm{C}$ for $30 \mathrm{~min}$. Reactions were terminated by addition of $450 \mu \mathrm{g}$ of bovine serum albumin and $50 \%$ trichloroacetic acid (ice cold) to a final concentration of $20 \%$. The reactions were incubated on ice for $5 \mathrm{~min}$ and centrifuged at $11,000 \times \mathrm{g}$ for $10 \mathrm{~min}$, and the supernatant was removed. The protein pellets were resuspended in $200 \mu \mathrm{l}$ of $50 \mathrm{mM}$ Tris$\mathrm{HCl}(\mathrm{pH} 8)$ and precipitated by addition of $150 \mu \mathrm{l}$ of $50 \%$ trichloroacetic acid (ice cold), centrifuged, and put through a third round of resuspension-precipitation to remove free ATP. The casein was finally resuspended in $200 \mu$ of $50 \mathrm{mM}$ Tris $(\mathrm{pH} \mathrm{8})$, and radioactivity was determined. Phosphatase activity was determined in a $200 \mu$; reaction volume containing $0.1 \mathrm{M}$ imidazole ( $\mathrm{pH} 7.0$ ), $0.1 \mathrm{mM}$ EDTA, and $0.1 \% \beta$-mercaptoethanol at $37^{\circ} \mathrm{C}$, using $10,000 \mathrm{cpm}$ of phosphorylated casein per assay. Reactions were incubated for $10 \mathrm{~min}$ and terminated by the addition of $800 \mu \mathrm{l}$ of $20 \%$ trichloroacetic acid. The reactions were incubated on ice for $10 \mathrm{~min}$ and centrifuged at $11,000 \times \mathrm{g}$ for $10 \mathrm{~min}$, and $150 \mu$ l was removed for determination of radioactivity.

\section{Northern Analysis}

Total RNA was isolated from rat brain and olfactory neuroepithelium by centrifugation through a cesium chloride cushion (Chirgwin et al., 1979), and polyadenylated RNA was isolated using the polyATract kit (Promega). The mRNA was electrophoresed in a formaldehyde-agarose gel and transferred to Nytran (Schleicher \& Schuell) as described previously (Sambrook et al., 1989). The multi-tissue blot was obtained from Clontech Laboratories, Inc. Tissue expression of PTP NE-3 was determined using a probe 
consisting of $2 \mathrm{~kb}$ of coding sequence, including the transmembrane domain and a portion of the first phosphatase domain. Analysis of $\beta$-actin expression was determined using a $2 \mathrm{~kb}$ CDNA probe. All blots were hybridized at high stringenecy $5 \times$ SSC, $5 \times$ Denhardt's solution, $0.1 \%$ SDS, $50 \mathrm{mM}$ sodium phosphate [pH 7], $100 \mu \mathrm{g} / \mathrm{ml}$ sheared salmon sperm DNA, 50\% formamide, $\left.42^{\circ} \mathrm{C}\right)$ and washed at high stringency $\left(0.2 \times \mathrm{SSC}, 0.1 \% \mathrm{SDS}, 65^{\circ} \mathrm{C}\right)$.

\section{In Situ Hybridization Histochemistry}

Rats (200-250 g, Sprague-Dawley males) anesthetized with sodium pentobarbital were perfused via the left cardiac ventricle with $200 \mathrm{ml}$ of $50 \mathrm{mM}$ sodium phosphate ( $\mathrm{pH}$ 7.5) containing 100 $\mathrm{mM} \mathrm{NaCl}$, followed by $200 \mathrm{ml}$ of Bouins fixative. After perfusion the olfactory system (olfactory turbinates and olfactory bulb) were dissected en bloc, postfixed for $3 \mathrm{hr}$ at room temperature, and cryoprotected overnight at $4^{\circ} \mathrm{C}$ in $50 \mathrm{mM}$ sodium phosphate (pH 7.5) containing $0.3 \mathrm{M}$ sucrose. Tissue was rapidly frozen in Tissue-Tek (Miles) by means of a liquid nitrogen-hexane bath and stored at $-75^{\circ} \mathrm{C}$. Tissue sections $(10 \mu \mathrm{m})$ were cut at $-18^{\circ} \mathrm{C}$ and thaw mounted on poly-L-lysine-coated slides.

Digoxigenin-labeled riboprobes were prepared from plasmids containing CDNA inserts for the genes of interest. These clones were modified such that poly $(A)$ tracts were removed from the templates used for riboprobe synthesis. Riboprobe transcriptions were performed essentially as described in the manufacturer's protocol (Boehringer Mannheim). Briefly, $1 \mu \mathrm{g}$ of linearized plasmid template was used in a transcription runoff labeling reaction typically yielding $10-50 \mu \mathrm{g}$ of labeled RNA with a digoxigenin-11-UTP incorporated every 20-25 nucleotides. Labeled riboprobe was ethanol precipitated to remove unincorporated labeled nucleotides. Alternatively, radiolabeled riboprobes were synthesized in the presence of [ ${ }^{35}$ S] UTP (New England Nuclear, Inc.). The radiolabeled probes were subsequently separated on a Sephadex G-50 column and precipitated prior to use.

Preceding hybridization, sections were warmed to room temperature and sequentially rehydrated in an ethanol series $(1 \mathrm{~min}$ each, $700 \%, 95 \%, 70 \%$, and $50 \%$ ) followed by $1 \mathrm{~min}$ in $2 \times \mathrm{SSC}$ (standard sodium citrate; $2 \times=0.3 \mathrm{M} \mathrm{NaCl}, 30 \mathrm{mM}$ sodium citrate $[\mathrm{pH} 7.0]$ ). Sections were then rinsed briefly in water, incubated for $10 \mathrm{~min}$ at room temperature in $0.25 \%$ acetic anhydride in $0.1 \mathrm{M}$ triethanolamine ( $\mathrm{pH} 8.0$ ), and finally, incubated for $10 \mathrm{~min}$ in phosphate-buffered saline. Sections were then dehydrated in the reverse order, from $2 \times$ SSC to $100 \%$ ethanol, and air dried. Hybridization mix included $10 \mathrm{mM}$ Tris- $\mathrm{HCl}(\mathrm{pH} 7.4), 50 \%$ for mamide, $0.3 \mathrm{M} \mathrm{NaCl}, 1 \mathrm{mM}$ EDTA, $10 \%$ dextran sulfate, $5 \times$ Denhardt's solution, $1 \mathrm{mg} / \mathrm{ml} \mathrm{tRNA}$, and $3 \mu \mathrm{g} / \mathrm{ml}$ riboprobe. The hybridization mix was heated to $65^{\circ} \mathrm{C}$ for $10 \mathrm{~min}$ before applying to dried sections $(\sim 40-80 \mu$ ) per section). Sections were coverslipped with a piece of Parafilm and placed in a humidified air incubator at $60^{\circ} \mathrm{C}$ for $5 \mathrm{hr}$. After hybridization, the slides were soaked in $2 \times$ SSC. to remove coverslips and allowed to rinse for $30 \mathrm{~min}$ (repeat once with fresh $2 \times \mathrm{SSC}$ ), followed by a $55^{\circ} \mathrm{C}$ wash in $50 \%$ formamide, $2 \times \mathrm{SSC}$ for $30 \mathrm{~min}$ and then a $37^{\circ} \mathrm{C}$ wash in $2 \times \mathrm{SSC}$ for $10 \mathrm{~min}$ repeated once. The slides were finally incubated for $30 \mathrm{~min}$ at $37^{\circ} \mathrm{C}$ in RNAase buffer $(55 \mathrm{mM} \mathrm{NaCl}, 10 \mathrm{mM}$ Tris- $\mathrm{HCl}$ [pH 7.5], $1 \mathrm{mM}$ EDTA) plus $20 \mu \mathrm{g} / \mathrm{ml}$ RNase A followed by a $60^{\circ} \mathrm{C}$ wash for $30 \mathrm{~min}$ in RNAase buffer (minus RNAase A).

Posthybridization visualization of hybridized digoxigeninlabeled riboprobe was accomplished by the Genius System (Boehringer Mannheim), following the manufacturer's protocol, using an anti-digoxigenin antibody conjugated to alkaline phosphatase with color development of nitroblue tetrazolium/ 5-bromo-4-chloro-3-indolyl phosphate (NBT/X-phusphate). Radioactive riboprobe signal from rat brain sections was detected by exposing the slides to a film (Kodak X-AR) for an appropriate length of time.

\section{Acknowledgments}

The authors would like to thank $M$. Brownstein for the rat brain cerebral cortex cDNA library, Zhao-Qin Bao and Walter Kostich for expert technical assistance, and Steve Sullivan for helpful suggestions. The sequences reported by B. Goldstein have been submitted with the accession numbers $L 11587$ and 112329 . This work was supported by grants from the University of Michigan Diabetes Research and Training Center (K.M.W.), General Clinical Research Center Grant M01-RR00042, the Waither Cancer institule, lie National Alliance for Research on Schizophrenia and Depression (K. J.M.), and National Institutes of Health grants DC-01964 (B. L. L.) and DK-18024 (J. E. D.).

The costs of publication of this article were defrayed in par: by the payment of page charges. This article must therefore be hereby marked "advertisement" in accordance with 18 USC Section 1734 solely to indicate this fact

Received April 22, 1993; revised June 23, 1993.

\section{References}

Anholt, R. R. H. (1993). Molecular Neurobiology of Olfaction. Crit. Rev. Neurobiol. 7, 1-22.

Atashi, J. R., Klinz, S. G., Ingrahiam, C. A., Matten, W. T. Schachner, M., and Maness, P. F. (1992). Neural cell adhesion molecules modulate tyrosine phosphorylation of tubulin in nerve growth cone membranes. Neuron 8, 831-842.

Barbacid, M., Lamballe, F., Pulido, D., and Klein, R. (1991). The trk family of tyrosine protein kinase receptors. Biochim. Biophys. Acta 1072, 115-127

Benowitz, L. 1., Apostolides, P. I., Perrone Bizzozero, I., Finklestein, S. P., and Zwiers, H. (1988). Anatomical distribution of the growth-associated protein GAP-43/B-50 in the adult brain. I. Neurosci. \&, 339-352.

Camera, C., and Harding, J. W. (1984). Thymidine incorporation in the olfactory epithelium of mice: early exponential response induced by olfactory neurectomy. Brain Res. 308, 63-68.

Chao, $M$. V. (1992). Neurotrophin receptors: a window into neuronal differentiation. Neuron 9, 583-593.

Chirgwin, J. M., Przybyla, A. E., MacDonald, R. J., and Rutter W. . (1979). Isolation of biologically active ribonucleic acid from sources enriched in ribonuclease. Biochemistry 18, 5294-5304. Chuong, C.M., Crossin, K. L., and Edelman, G. M. (1987). Sequential expression and differential function of multiple adhesion molecules during the formation of cerebellar cortical layers. J. Cell Biol. 104, 331.342.

Cunningham, B. A., Hemperly, I. J., Murray, B. A., Prediger, E. A. Brackenbury, R., and Edelman, G.M. (1987). Neural cell adhesion molecule: structure, immunoglobulin-like domains, cell surface modulation, and alternative RNA splicing. Science 236, 799-806. De La Monte, S. M., Federoff, H. J., Ng, S.-C., Grabcyk, E., and Fishman, M. C. (1989). GAP-43 gene-expression during develop ment: persistance in a distinctive set of neurons in the mature central nervous system. Dev. Brain Res. 46, 161-168.

Dumphy, W. G., and Kumagai, A. (1991). The cdc25 protein contains an intrinsic phosphatase activity. Cell 67, 189-196.

Elices, M. J., Osborn, L., lakada, Y., Crouse, C., Luhowskyj, S., Hemler, M. E., and Lobb, R. R. (1990). VCAM-1 on activated endothelium interacts with the leukocyte integrin VLA-4 at a site distinct from the VLA-4/fibronectin binding site. Cell 60, 577-584.

Elkins, T., Zinn, K., McAllister, L., Hoffman, F. M., and Goodman, C. S. (1990). Genetic analysis of a Drosophila neurai cell adhesion molecule: interaction of fasciclin I and Abelson tyrosine kinase mutations. Cell $60,565-575$.

Frohman, M. A. (1990). RACE: rapid amplification of CDNA ends In PCR Protocols, M. A. Innis, D. H. Gelfand, J. I. Sninsky, and T. J. White, eds. (San Diego: Academic Press, inc.), pp. 28-38. Gertler, F. B., Bennett, R. L., Clark, M. J., and Hoffmann, F. M. (1989). Drosophila ab/ tyrosine kinase in embryonic CNS axons: a role in axonogenesis is revealed through dosage-sensitive interactions with disabled. Cell 58, 103-113.

Gierasch, L. M. (1989). Signai sequences. Biochemistry 28, 923930.

Graziadei, P.P.C., and Monti-Graziadei, C. A. (1978). Continuous cell renewal in the olfactory system. Handbook of Sensory Physi- 
ology, M. Jacobson, eds. (New York: Springer-Verlag), pp. 5583.

Grenningloh, G., Bieber, A. J., Rehm, E. J., Snow, P. M., Traquina, Z. R., Hortsch, M., Patel, N. H., and Goodman, C. S. (1990). Molecular genetics of neuronal recognition in Drosophila: evolution and function of immunoglobulin superfamily cell adhesion molecules. Cold Spring Harbor Symp. Quant. Biol. 55, 327-340.

Grunstein, M., and Hogness, D. S. (1975). Colony hybridization: a method for the isolation of cloned DNAs that contain a specific gene. Proc. Natl. Acad. Sci. USA 72, 3961-3965.

Gu, M., York, J. D., Warshawsky, I., and Majerus, P. W. (1991). Identification, cloning, and expression of a cytosolic megakaryocyte protein-tyrosine-phosphatase with sequence homology to cytoskeletal protein 4.1. Proc. Natl. Acad. Sci. USA 88, 5867-5871. Guan, K. L., and Dixon, J. E. (1991). Eukaryotic proteins expressed in Escherichia coli: an improved thrombin cleavage and purification procedure of fusion proteins with glutathione S-transferase. Anal. Biochem. 192, 262-267.

Guan, K. L., Haun, R. S., Watson, S. J., Geahlen, R. L., and Dixon, J. E. (1990). Cloning and expression of a protein-tyrosine-phosphatase. Proc. Natl. Acad. Sci. USA 87, 1501-1505.

Hariharan, I. K., Chuang, P. T., and Rubin, G. M. (1991). Cloning and characterization of a receptor-class phosphotyrosine phosphatase gene expressed on central nervous system axons in Drosophila melanogaster. Proc. Natl. Acad. Sci. USA 88, 11266-11270.

Howard, P. K., Sefton, B. M., and Firtel, R. A. (1992). Analysis of a spatially regulated phosphotyrosine phosphatase identifies tyrosine phosphorylation as a key regulatory pathway in Dictyostelium. Cell 71, 637-647.

Hynes, R. O., and Lander, A. D. (1992). Contact and adhesive specificities in the associations, migrations, and targeting of cells and axons. Cell 68, 303-322.

Ibáñez, C. F., Ebendal, T., Barbany, G., Murray-Rust, J., Blundell, T. L., and Persson, H. (1992). Disruption of the low affinity receptor-binding site in NGF allows neuronal survival and differentiation by binding to the trk gene product. Cell 69, 329-341.

Jirik, F. R., Harder, K. W., Melhado, I. G., Anderson, L. L., and Duncan, A. M. (1992). The gene for leukocyte antigen-related tyrosine phosphatase (LAR) is localized to human chromosome $1 \mathrm{p} 32$, a region frequently deleted in tumors of neuroectodermal origin. Cytogenet. Cell Genet. 61, 266-268.

Kaplan, D. R., Martin-Zanca, D., and Parada, L. F. (1991). Tyrosine phosphorylation and tyrosine kinase activity of the trk protooncogene product induced by NGF. Nature 350, 158-160.

Klein, R., Parada, L. F., Coulier, F., and Barbacid, M. (1989). trkB, a novel tyrosine protein kinase receptor expressed during mouse neural development. EMBO J. 8, 3701-3709.

Klein, R., Martin-Zanca, D., Barbacid, M., and Parada, L. F. (1990). Expression of the tyrosine kinase receptor gene trkB is confined to the murine embryonic and adult nervous system. Development 109, 845-50.

Klein, R., Jing, S., Nanduri, V., O'Rourke, E., and Barbacid, M. (1991). The trk proto-oncogene encodes a receptor for nerve growth factor. Cell 65, 189-197.

Kozak, M. (1991). Structural features in eukaryotic mRNAs that modulate the initiation of translation. J. Biol. Chem. 266, 1986719870.

Kremer, N. E., D'Arcangelo, G., Thomas, S. M., DeMarco, M. Brugge, J. S., and Halegoua, S. (1991). Signal transduction by nerve growth factor and fibroblast growth factor in PC12 cells requires a sequence of SrC and Ras actions. J. Cell Biol. 115, 809819.

Krueger, N. X., Streuli, M., and Saito, H. (1990). Structural diversity and evolution of human receptor-like protein tyrosine phosphatases. EMBO J. 9, 3241-3252.

Lai, C., Brow, M. A., Nave, K.-A., Noronha, A. B., Quarles, R. H. Bloom, F. E., Milner, R. J., and Sutcliffe, J. G. (1987). Two form of 1B235/myelin associated glycoprotein, a cell adhesion molecule for postnatal neural development, are produced by alterna- tive splicing. Proc. Natl. Acad. Sci. USA 84, 4337-4341.

Largent, B. L., Sosnowski, R. G., and Reed, K. K. (1993). Directed expression of an oncogene to the olfactory neuronal lineage in transgenic mice. J. Neurosci. 13, 300-312.

Le Beau, J. M., Tedeschi, B., and Walter, B. (1991). Increased expression of $\mathrm{pp}^{60} \mathrm{C}-\mathrm{src}$ protein-tyrosine kinase during peripheral nerve regeneration. J. Neurosci. Res. 28, 299-309.

Lindner, J., Rathjen, F. G., and Schachner, M. (1983). L1 mono- and polyclonal antibodies modify cell migration in early postnatal mouse cerebellum. Nature 305, 427-430.

Lombroso, P. J., Murdoch, G., and Lerner, M. (1991). Molecular characterization of a protein-tyrosine-phosphatase enriched in striatum. Proc. Natl. Acad. Sci. USA 88, 7242-7246.

Maness, P. F., and Matten, W. T. (1990). Tyrosine phosphorylation of membrane-associated tubulin in nerve growth cones enriched in $\mathrm{pp}^{60} \mathrm{C}$-src. Ciba Found. Symp. 150, 57-78.

Maness, P. F., Aubury, M., Shores, C. G., Frame, L., and Pfenniger, K. H. (1988). c-src gene product in developing rat brain is enriched in nerve growth cone membranes. Proc. Natl. Acad. Sci. USA 85, 5001-5005.

Margolis, F. L. (1985). Olfactory marker protein: from PAGE band to cDNA clone. Trends Neurosci. 8, 542-546.

Martin-Zanca, D., Barbacid, M., and Parada, L. F. (1990). Expression of the trk proto-oncogene is restricted to the sensory cranial and spinal ganglia of neural crest origin in mouse development. Genes Dev. 4, 683-694.

Matten, W. T., Aubry, M., West, J., and Maness, P. F. (1990). Tubulin is phosphorylated at tyrosine by $\mathrm{pp}^{60} \mathrm{C}$-src in nerve growth cone membranes. J. Cell Biol. 117, 1959-1970.

Matthews, R. J., Cahir, E. D., and Thomas, M. L. (1990). Identification of an additional member of the protein-tyrosine-phosphatase family: evidence for alternative splicing in the tyrosine phosphatase domain. Proc. Natl. Acad. Sci. USA 87, 4444-4448.

Miragall, F., Kadmon, G., Husmann, M., and Schachner, M. (1988). Expression of cell adhesion molecules in the olfactory system of the adult mouse: presence of the embryonic form of N-CAM. Dev. Biol. 129, 516-531.

Morrison, E. E., and Costanzo, R. M. (1990). Morphology of the human olfactory epithelium. J. Comp. Neurol. 297, 1-13.

Nef, P., Hermans-Borgmeyer, I., Artieres-Pin, H., Beasley, L., Dionne, V. E., and Heinemann, S. F. (1992). Spatial pattern of recep tor expression in the olfactory epithelium. Proc. Natl. Acad. Sci. USA 89, 8948-8952.

Neve, R. L., Finch, E. A., Bird, E. D., and Benewitz, L. I. (1988). Growth-associated protein GAP-43 is expressed selectively in associative regions of the adult human brain. Proc. Natl. Acad. Sci. USA $85,3638-3642$.

Ngai, J., Chess, A., Dowling, M. M., Necles, N., Macagno, E. R. and $A x e l, R$. (1993). Coding of olfactory information: topography of odorant receptor expression in the catfish olfactory epithelium. Cell 72, 667-680.

Oakley, B., and Riddle, D. R. (1992). Receptor cell regeneration and connectivity in olfaction and taste. Exp. Neurol. 115, 50-54. Okayama, H., Kawaichi, M., Brownstein, M., Lee, F., Yokota, T., and Arai, K. (1987). High-efficiency cloning of full-length cDNA construction and screening of cDNA expression libraries for mammalian cells. Meth. Enzymol. 154, 3-28.

Patthy, L. (1990). Homology of a domain of the growth hormone prolactin receptor family with type III modules of fibronectin. Cell 61, 13-14.

Perkins, L. A., Larsen, I, and Perrimon, N. (1992). corkscrew encodes a putative protein tyrosine phosphatase that functions to transduce the terminal signal from the receptor tyrosine kinase torso. Cell 70, 225-236.

Pingel, J. T., and Thomas, M. L. (1989). Evidence that the leukocyte-common antigen is required for antigen-induced $T$ lymphocyte proliferation. Cell 58, 1055-1065. 
Pot, D. A., Woodford, T. A., Remboutsika, E., Haun, R. S., and Dixon, J. E. (1991). Cloning, bacterial expression, purification, and characterization of the cytoplasmic domain of rat LAR, receptor-like protein tyrosine phosphatase. J. Biol. Chem. 266, 19688-19696.

Ramakers, G. J. A., Verhaagen, J., Oestreicher, A. B., Margolis, F. L., Van Bergen en Henegouwen, P. M. P., and Gispen, W. H. (1992). Immunolocalization of B-50 (GAP-43) in the mouse olfactory bulb: predominant presence in preterminal axons. J. Neurocytol. 21, 853-869.

Reed, R. R. (1992). Signaling pathways in odorant detection. Neuron 8, 205-209.

Ressler, K. J., Sullivan, S. L., and Buck, L. B. (1993). A zonal organization of odorant receptor gene expression in the olfactory epithelium. Cell 73, 597-609.

Rodriguez-Tebar, A., Dechant, G., and Barde, Y.-A. (1991). Neurotrophins: structural relatedness and receptor interactions. Phil. Trans. Roy. Soc. Lond. (B) 331, 255-258.

Rutishauser, U., and Jessell, T.M. (1988). Cell adhesion molecules in vertebrate neural development. Physiol. Rev. 68, 819-857.

Samanen, D. W., and Forbes, W. B. (1984). Replication and differentiation of olfactory receptor neurons following axotomy in the adult hamster: a morphometric analysis of post-natal neurogenesis. J. Comp. Neurol. 225, 201-211.

Sambrook, J., Fritsch, E. F., and Maniatis, T. (1989). Molecular Cloning: A Laboratory Manual, Second Edition (Cold Spring Harbor, New York: Cold Spring Harbor Laboratory).

Schwartz Levey, M., Chikaraishi, D. M., and Kauer, J. S. (1991). Characterization of potential precursor populations in the mouse olfactory epithelium using immunocytochemistry and autoradiography. J. Neurosci. 11, 3556-3564.

Schwob J. E., Farber, N. B., and Gottlieb, D. I. (1990). Neurons of the olfactory epithelium in adult rats contain vimentin. I. Neurosci. 6, 208-217.

Schwob, J. E., Mieleszko Szumowski, K. E., and Stasky, A. A. (1992). Olfactory sensory neurons are trophically dependent on the olfactory bulb for their prolonged survival. !. Neurosci. 12 , 3896-3919.

Shen, S. H. Bastien, L., Posner, B. I., and Chretien, P. (1991). A protein tyrosine phosphatase with sequence similarity to the $\mathrm{SH} 2$ domain of the protein-tyrosine kinases. Nature $352,736-$ 739.

St. Johnston, D., and Nusslein-Volhard, C. (1992). The origin of pattern and polarity in the Drosophila embryo. Cell 68, 201-219. Staunton, D. E., Marlin, S. D., Stratowa, C., Dustin, M. L., and Springer, T. A. (1988). Primary structure of intracellular adhesion molecule 1 (ICAM-1) demonstrates interaction between members of the immunoglobulin and integrin supergene families. Cell 52, 925-933.

Streuli, M., Krueger, N. X., Hall, L. R., Schlossman, S. F., and Saito, 11. (1980). A new member of the immunoglobulin superfamily that has a cytoplasmic region homologous to the leukocyte common antigen. J. Exp. Med. 168, 1523-1530.

Streuli, M., Krueger, N. X., Tsai, A. Y., and Saito, H. (1989). A family of receptor-linked protein tyrosine phosphatases in humans and Drosophila. Proc. Natl. Acad. Sci. USA 86, 8698-8702.

Streuli, M., Krueger, N. X., Ariniello, P. D., Tang, M., Munro, J. M., Blattler, W. A., Adler, D. A., Disteche, C. M., and Saito, H. (1992). Expression of the receptor-linked protein tyrosine phosphatase LAR: proteolytic cleavage and shedding of the CAM-like extracellular region. EMBO J. 11, 897-907.

Swarup, G., Kamatkar, S., Radha, V., and Rcma, V. (1991). Molecular cloning and expression of a protein-tyrosine phosphatase showing homology with transcription factors Fos and Jun. FEBS Lett. 280, 65-69.

Tian, S.-S., Tsoulfas, P., and Zinn, K. (1991). Three receptor-linked protein-tyrosine phosphatases are selectively expressed on cen tral nervous system axons in the Drosophila embryo. Cell 67, 675-685.
Trowbridge, 1. S. (1991). CD45, a prototype for transmembrane protein tyrosine phosphatases. ). Biol. Chem. 266, 23517-23520. Verhaagen, J., Oestreicher, A. B., Gispen, W. H., and Margolis, F. L. (1989). The expression of the growth associated protein $B 50$ GAP43 in the olfactory system of neonatal and adult rats. J. Neurosci. 9, 683-691.

Verhaagen, I., Oestricher, A. B., Grillo, M., Khew-Goodall, Y.-5. Gispen, W. H., and Margolis, F. L. (1990). Neuroplasticity in the olfactory system: differential effects of central and peripheral lesions of the primary olfactory pathway on the expression of B-50/GAP43 and the olfactory marker protein. J. Neurosci. Res. 26, 31-44.

Viereck, C., Tucker, R. P., and Matus, A. (1989). The adult rat olfactory system expresses microtubule-associated proteins found in the developing brain. J. Neurosci. 9, 3547-3557.

von Heijne, G. (1990). The signal peptide. J. Membr. Biol. 115 195-201.

Williams, A. F., and Barrlay, A. N. (1988). The immunoglobulin superfamily: domains for cell surface recognition. Annu. Rev. Immunol. 6, 381-405.

Yang, Q., and Tonks, N. K. (1991). Isolation of a cDNA clone encoding a human protein-tyrosine phosphatase with homology to the cytoskeletal-associated proteins band 4.1, ezrin, and talin. Proc. Natl. Acad. Sci. USA 88, 5949-5953.

Yang, X., Seow, K. T., Bahri, S. M., Oon, S. H., and Chia, W. (1991). Two Drosophila receptor-like tyrosine phosphatase genes are expressed in a subset of developing axons and pioneer neurons in the embryonic CNS. Cell 67, 661-673.

Yu, Q., Lenardo, T., and Weinberg, R. A. (1992). The N-terminal and $\mathrm{C}$-terminal domains of a receptor tyrosine phosphatase are associated by non-covalent linkage. Oncogene 7, 1051-1057.

Zhang, Z. Y., Clemens, J. C., Schubert, H. L., Stuckey, J. A. Fischer, M. W. Hume, D. M. Saper, M. A., and Dixon, I. E. (1992). Expression, purification, and physicochemical characterization of a recombinant Yersinia protein tyrosine phosphatase. J. Biol Chem. 267, 23759-23766.

Zhao, Z., Bouchard, P., Diltz, C. D., Shen, S.-H., and Fischer E. H. (1993). Purification and characterization of a protein tyrosine phosphatase containing $\mathrm{SH} 2$ domains. J. Biol. Chem. 268 2816-2820.

\section{GenBank Accession Number}

The GenBank accession number for the nucleotide sequence reported in this paper is L19933. 